Article

\title{
Life-Cycle Break-Even Analysis of Electric Carsharing: A Comparative Study in China
}

\author{
Jingjing Jia ${ }^{1}$, Shujie Ma ${ }^{2}$, Yixi Xue ${ }^{3} \mathbb{D}$ and Deyang Kong ${ }^{2, *}$ \\ 1 School of Business, Shanghai Dianji University, Shanghai 201306, China; Gabriella_jingjing@aliyun.com \\ 2 School of Automotive Studies, Tongji University, Shanghai 201804, China; mashujie_tj@163.com \\ 3 School of Management, Shanghai University, Shanghai 200444, China; nkxueyixi@sina.com \\ * Correspondence: kongdeyang@tongji.edu.cn
}

Received: 22 July 2020; Accepted: 7 August 2020; Published: 14 August 2020

\begin{abstract}
Electric carsharing (ECS) is a potential option to address the problem of unsustainability in the transportation sector. The business-to-consumer model of ECS, which is one of several different electric carsharing models, has gained much popularity in recent years. Generating sufficient revenue to cover costs is a critical factor for ECS companies to maintain healthy development. This study makes an economic analysis, on the basis of life-cycle cost and monetary revenue associated with the operation of ECS, of two Chinese ECS companies: EVCARD and LCCS. Based on data gathered by field investigation, this study aims to determine the break-even moment for each company's main vehicle models by means of the net present value method. The results show that EVCARD achieved an earlier break-even moment than LCCS. The break-even moment of Chery eQ of EVCARD was the shortest of all the vehicle models, at only $181.3 \mathrm{~min}$. Moreover, a sensitivity analysis was conducted to portray how different cost-related and revenue-related factors influence the break-even moment. Our findings indicate that a wide difference exists in terms of the influence of different factors on the break-even moment. Among these, the manufacturer's suggested retail price is the most influential variable, followed by the unit rental price. The reaction of the break-even moment to the market price of a charging pile and the non-rental revenue per vehicle—especially the latter-was found to be negligible in the sensitivity analysis.
\end{abstract}

Keywords: electric carsharing; break-even moment; life-cycle cost; sensitivity analysis; EVCARD; LCCS

\section{Introduction}

In recent years, the sharing economy has experienced rapid growth due to its potential for sustainable development by transforming the traditional ownership of goods into access and thus bringing down consumption and improving the efficiency of resource utilization [1,2]. While there is no agreement on its definition, most scholars see the sharing economy as a disruptive innovation which transforms the way that business is done and creates an opportunity for new business models [3].

Owing in large part to the strength of the Internet and mobile technologies, the sharing economy has infiltrated into a variety of sectors of the economy [4]. The mobility sector, which is one of the main unsustainable fields due to its large and increasing contribution to high oil dependency and global air pollution [5], as well as traffic congestion and parking difficulties, is becoming a critical promising part of the sharing economy [6]. Specifically, carsharing (CS) has become the dominant sharing model in the field of urban mobility [7], changing the traditional mobility model of private vehicle ownership into accessing and using non-ownership vehicles and thus contributing to sustainable development by reducing the number of vehicles in cities, saving energy and static land consumption, reducing pollution, and lowering carbon emissions [8,9]. Within CS, two prevailing models are observed: one 
is the peer-to-peer (P2P) model, in which peers (individuals) share owned vehicles through digital platforms such as Uber and DiDi, and the other is the business-to-consumer (B2C) model, in which vehicles are purchased and owned by corporations rather than individuals [10], such as Autolib and Car2go.

The B2C model is essentially a purely platform-driven commercial model, and it has been developing especially quickly in the past decades [11]. However, successfully operating a B2C CS company is never an easy prospect [4]. Many financial challenges are faced by companies when they operate and expand their businesses. This challenge is even more serious for electric carsharing (ECS); i.e., the combination of electric vehicles (EVs) and CS. In contrast to traditional combustion engine vehicles, EVs are a kind of electric-driven technology that can greatly decrease carbon emissions, especially when the electricity is generated by clean energy sources [12]. ECS represents a comprehensive innovation in terms of patterns, technology, and management in comparison to the CS service, which is regarded as having the potential to overcome the disadvantages of EVs such as the higher initial purchasing cost and longer charging time, further allowing CS to become a more sustainable means of transport by combing the advantages of EVs and CS [13]. However, the operation of an ECS service is more difficult than the standard model. The main reason for this is that many additional planning decisions must be considered compared to conventional CS, for example, avoiding battery depletion [14]. EVs must be charged during their idle time, and companies must consider the battery status when relocating shared EVs. These problems will increase the difficulty of balancing the revenue and cost for ECS companies.

According to the study of Lagadic et al., only one company-Swiss Cooperative Mobility carsharing-has publicly demonstrated that it is profitable [15]. Most companies-especially ECS companies-are in an actual state of deficit, and some have even failed. For example, Autolib, which was launched by the City of Paris in 2011 and operated by the Bolloré industrial group, used to be the largest one-way ECS in the world; however, it had to be terminated in July 2018 due to significant losses.

The business model literature emphasizes that it is vital for companies to generate sufficient revenue to cover costs arising from creating and delivering value to customers [16,17]. However, the pursuit of profit is generally considered to "harm social cohesion and hamper pro-social behavior" when the sharing economy is discussed [3]. While the awareness of the need to increase the profitability of ECS businesses has been increasing recently, the relevant scholarly literature to date has not sufficiently reflected this urgency. Existing academic studies have mainly focused on the motivation of users [18-20], the optimal planning of an ECS system [13,21,22], and the benefits of ECS in the sustainable mobility system $[23,24]$. Some interesting research questions, however, are seldom discussed, such as the following: Why is it difficult for ECS companies with the B2C model to make profits? Under what conditions can operators achieve the balance of revenues and costs, and what is the break-even point? Which factors can significantly affect this balance? This paper aims to respond to the above questions by performing a life-cycle break-even analysis of ECS companies in China.

What is the contribution of this paper? In the competitive market, increasing the efficiency of the economics of ECS is essential to unlock its industrial potential. To attract sufficient investment, ECS companies must gain benefits to justify their costs [25]. Thus, the urgent need for a cost-benefit analysis is increasing; in particular demand is the life-cycle break-even analysis, which economically focuses on all costs occurred during the lifecycle of an ECS project, from construction and operation to residual value recovery. It is important to support the decision-making and cost management of ECS companies and help them form reasonable expectations. However, a brief review of the literature shows that relevant studies mainly focus on analyzing the benefits and costs of EVs and benefits of CS or ECS from the perspectives of individuals (users) and society.

Some studies in this field concentrate on comparing the benefits, especially social benefits (e.g., $\mathrm{CO}_{2}$ reduction) of EVs and traditional vehicles [26-31]. For example, Noel and McCormack [26] found that V2G-capable electric school buses are more economic than traditional diesel school buses for school 
operators. It can provide savings of $\$ 6070$ per seat, and the school can make a profit after five years of operation. Gopal et al. [26] found that the transition from traditional internal combustion engine vehicles (ICEVs) to EVs is a cost-effective strategy in terms of marginal abatement costs of carbon in the long term in China.

Some studies focused on discussing the total costs of ownership (TCO) of EVs in comparison to traditional vehicles [32-36]. For example, Moon and Lee [36] constructed an EV investment model for consumers by adopting TCO, and the results showed EVs are more cost-effective than traditional vehicles. However, Velzen et al. [35] found, through a developed comprehensive EV TCO forecasting framework, that the TCO of EVs are not necessarily lower than those of traditional vehicles. Tanco et al. [37] compared the different break-even year of battery electric trucks in five Latin-American countries based on a quantitative linear model.

Other studies focused on the economic and social benefits of CS/ECS for users and society [38-40]. For example, Fellows and Pitfield [38] employed cost-benefit analysis techniques to examine the economic benefits of CS. The results showed that CS can bring great economic benefits (journey costs, average speeds, fuel, accidents, and emissions) for both individuals and society even with conservative participation rates and relative low patronage. Rabbitt and Ghosh [39] assessed the economic and environmental influence of CS in Ireland, and the results showed CS can benefit both individuals in terms of travel cost savings and society in terms of $\mathrm{CO}_{2}$ emission reduction.

The life-cycle break-even analysis in this paper is novel because its focus is on ECS companies with the B2C model, and only the monetary economic revenues of ECS companies are calculated without including the non-monetary benefits, such as the environment benefits to society. This can provide a relatively objective decision-making basis for ECS companies.

Why choose Chinese cases? Typically, life-cycle break-even analysis is a highly case-specific method. In this paper, two representative cases of ECS with B2C models in China were selected and compared: EVCARD in Shanghai and Liancheng Electric Carsharing Company (hereinafter referred to as LCCS) in Shenzhen. EVCARD is now the largest ECS company in China. By the end of 2018, it had 3.4 million registered members, operated 13,000 stations, and had a whole fleet of more than 45,000 EVs in 64 Chinese cities [41]. Among these cities, Shanghai has the largest number of stations (3673), and more than 8000 shared EVs are running in this city. Therefore, its break-even analysis results can represent a better level of ECS in China. LCCS is a pilot demonstration project launched by the local government. This platform is operated by multiple actors including government, enterprises, and institutions. Besides Shenzhen, some other local governments also try to support and promote ECS. Therefore, the analysis of LCCS can provide some useful insights for these local governments, especially those who try to explore the cooperating mechanism of university-industry research. Its break-even analysis results can also reflect the general status of such companies. Through in-depth field investigation, life-cycle break-even analysis of the two cases was performed based on empirical data. China, a developing country in the transition to a low-carbon economy, is experiencing a rapid growth in the sharing economy. For three consecutive years (2017-2019), the Chinese premier has called for rapid and healthy development of the sharing economy in his government work report [42-44]. According to the statistics of the State Information Center, the trading volumes of China's sharing economy amounted to CNY 2942 billion in 2018, which was an increase of $41.6 \%$ over the previous year [45]. Among all the application areas, the shared mobility sector is one of the most critical and potential fields [5]. In 2014, Guidance on Accelerating the Promotion and Application of New Energy Vehicles issued by General Office of the State Council actively encouraged the investment and financing innovation and the exploration of ECS with B2C models in personal mobility [46]. From then on until 2017, ECS with B2C models developed rapidly. A study from iResearch Research Group revealed that companies engaged in shared mobility service were valued at $\$ 116.9$ billion in 2017 [47], and the statistics of the State Information Center revealed the financing volumes of the shared mobility sector reached CNY 107.2 billion in 2017 [48], both of which were the highest in comparison to other shared industries in China. The study by Roland Berger [49], published in April 2017, further predicated 
that the number of shared cars in China would maintain a compound annual growth rate of $45 \%$ and reach 600,000 by 2025 . However, the rapid growth trend changed since the second half of 2017 . Many ECS companies closed [50]. Car2go, for example, which entered the Chinese market four years ago, officially withdrew on June 30, 2019. The financing volumes of the shared mobility sector also sharply dropped to CNY 419 billion in 2018, with a decrease rate of $61 \%$ [48]. The core reason for the change is mainly the difficulties in profitability. Therefore, the study of Chinese cases can provide interesting insights into the development of ECS with the B2C model, especially for developing and low-carbon transition countries.

The remainder of this paper is organized as follows. In Section 2, we present the details of the two cases. Section 3 introduces the research methods and data collection. Section 4 shows the break-even analysis results of the two cases and a sensitivity analysis to identify the effect of different factors. Section 5 presents a discussion and the conclusion of this paper.

\section{EVCARD and LCCS}

\subsection{EVCARD}

In April 2011, eight countries including China and the United States signed the Electric Vehicle Initiative, in which Shanghai was selected as the first international demonstration city of EVs in China. Shanghai International Automobile City (SIAC), a municipal owned enterprise, was then established to carry out the international EV demonstration in Shanghai. In July 2013, SIAC launched the first ECS program in China, named EVCARD, which was formally put into operation in January 2015. In October 2016, Shanghai Automobile Group Co., Ltd. (SAIC Motor) and SIAC jointly invested in the establishment of the Universal Car Sharing Co., Ltd. (hereinafter referred to as UCS), which became the operator of EVCARD.

The operation details of EVCARD are reported in Table 1. EVCARD is essentially dominated by a state-owned automobile enterprise (SAIC). All vehicles in the fleet were purchased by EVCARD itself, and all the vehicle models in operation are presented in Figure 1, among which Roeway E50 and Chery eQ are the two main models. Consumers can use these vehicles after registration and return them at any operational station at any time. The maintenance of the fleet is provided by EV manufactures, and EVCARD pays the maintenance fees to the manufacturers. The stations are mainly distributed in industrial parks, traffic hubs, universities, and business centers. In the early days of EVCARD's development, many parking areas were provided by the local government or universities for free. For example, Tongji station is a cooperative between EVCARD and Tongji University. Tongji University provides a free parking area for EVCARD on campus. The booking requests of Tongji station rank second among all EVCARD stations in Shanghai [14]. However, with the continuous expansion of business, more and more parking areas are cooperative with business organizations or rented by EVCARD. The charging facilities in the stations are provided by third-party organizations including Shanghai Zheda Science and Technology Development Co., Ltd. and Shanghai Xuandao New Energy Technology Co., Ltd. EVCARD pays these third-party organizations for purchase, installation, and subsequent maintenance. 
Table 1. Operation details of EVCARD.

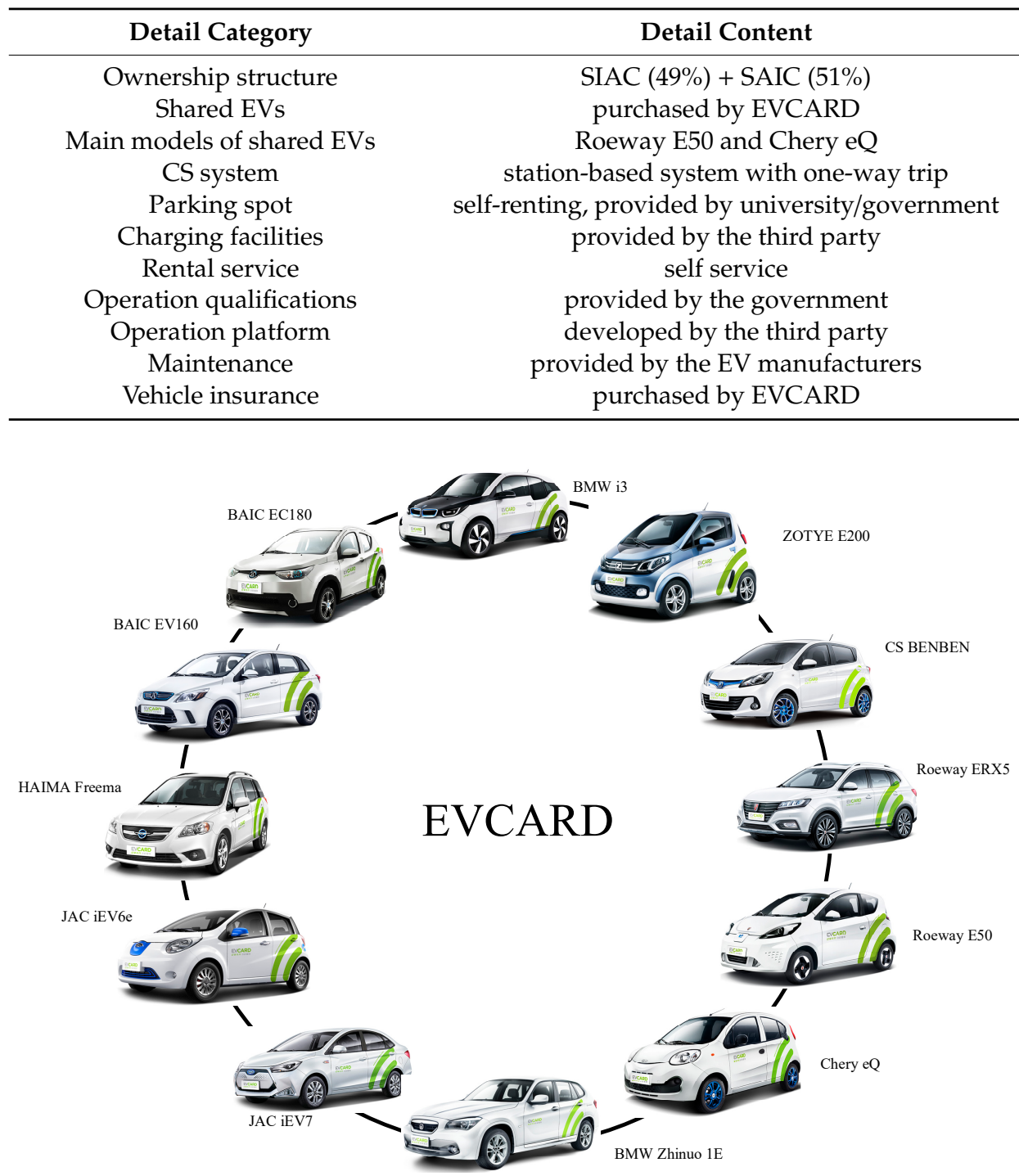

Figure 1. Vehicle models of EVCARD.

\subsection{LCCS}

In 2014, Shenzhen Urban Development Research Center, Tongji University, and the State Information Center formed a research group under the help of the Shenzhen Development and Reform Commission. This research group successfully applied for the 2014 National Science and Technology Support Program-Technology Integration and Demonstration Application Project of Electric Carsharing in Shenzhen (TIDA project). In June 2015, Longgang District Government of Shenzhen signed a strategic cooperation memorandum with Tongji University in which they agreed to explore the business model innovation of ECS with the fund of the TIDA project. In August 2015, LCCS was established based on the memorandum with a registered capital of CNY 50 million, and it undertook the task of promoting more than 3000 shared EVs in Shenzhen.

The operation details of LCCS are reported in Table 2. It can be seen that LCCS is a mixed ownership enterprise jointly owned by Shenzhen Huacheng Transportation Company (HC), Shanghai Jiexing Electric Vehicle Company (JXmobi), Shenzhen Wankede Investment Development Company (WANKEDE), and Shenzhen Zhongwanbao Real Estate Company (ZWB). HC is absolutely controlled by the Longgang District Government. JXmobi was founded in June 2008 and was a platform company for the R\&D transfer of EVs by Tongji University; it was responsible for the development of the 
App-based digital platform. Obviously, the operation of LCCS is indeed dominated by the local government and Tongji University. All vehicles in the fleet were purchased by LCCS itself, among which JAC IEV5, BAIC EV160, and ZD D2 are the three main models. The charging facilities in the stations are provided by the third-party organization Shenzhen Cheku Charging Pile Technology Company. The other operation details of LCCS are similar to those of the EVCARD.

The main partnerships of LCSS are presented in Figure 2. As shown in the figure, LCCS experienced a transition from the "single operator" model to the "multi-operators + single platform" model, which was a key move. The main purpose was to cope with operational difficulty. On the one hand, LCCS found it very difficult to achieve the promotion target of 3000 shared EVs alone after several months of operation. On the other hand, were are already several ECS companies in Shenzhen such as Shenzhen Chepu Intelligent Transportation Service Company (Chepu), Shenzhen ZTE New Energy Vehicle Technology Company, Ponycar, and BYD. In order to integrate these resources and achieve promotion objectives, LCCS decided to develop a unified App-based digital platform and encouraged other ECS companies to join in the platform. In August 2016, Shenzhen Tongda Network Technology Company (TD), which was invested by JXmobi, was chosen to develop the new digital platform for LCCS. By the end of 2018, two companies (Chepu and Ponycar) had joined in this digital platform, and LCCS became the largest ECS company in Shenzhen, operating 3030 shared EVs.

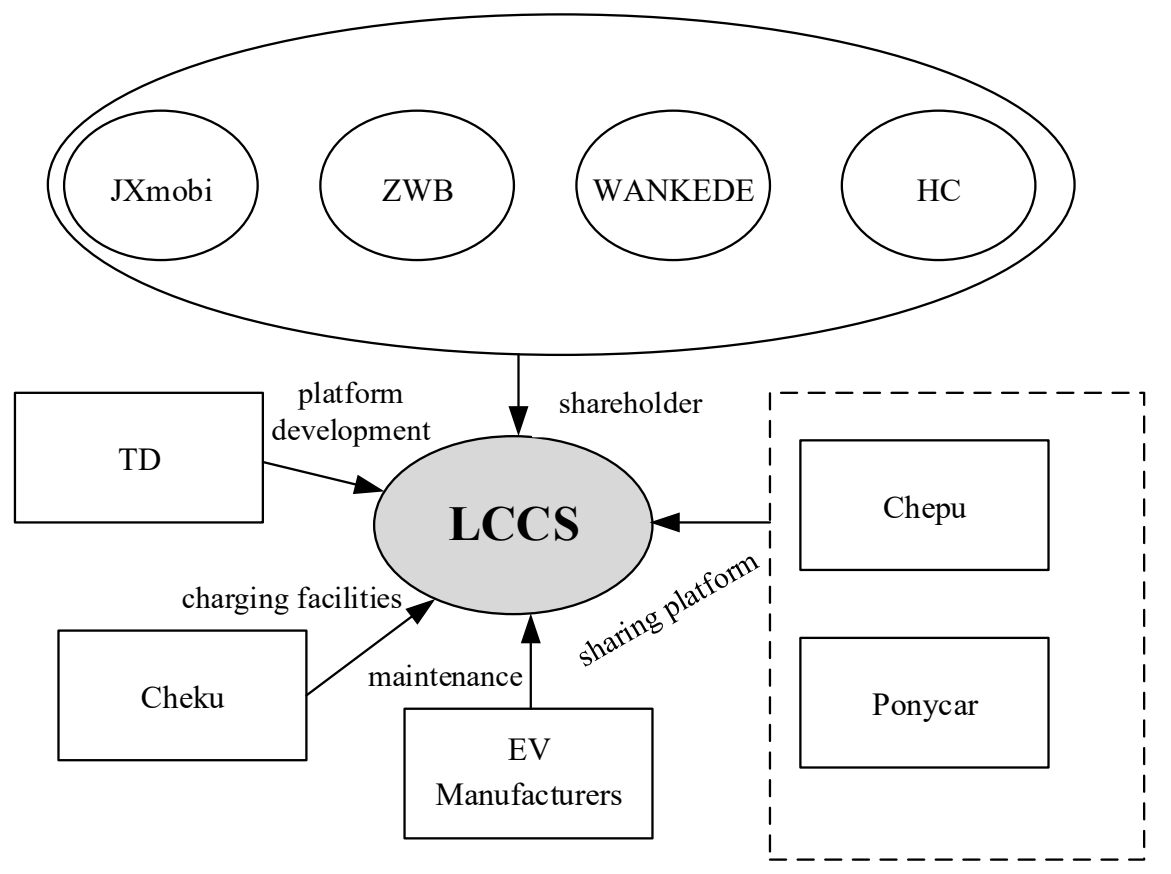

Figure 2. Main partners of LCCS.

Table 2. Operation details of LCCS.

\begin{tabular}{cc}
\hline Detail Category & Detail Content \\
\hline Ownership structure & JXmobi $(8 \%)+$ WANKEDE $(34 \%)+$ ZWB $(33 \%)+$ HC (25\%) \\
Shared EVs & purchased by LCCS \\
Main models of shared EVs & JAC IEV5, BAIC EV160, Geely ZD D2 \\
CS system & station-based system with one-way trip \\
Parking spot & government/business cooperation \\
Charging facilities & provided by third party \\
Rental service & self service \\
\hline
\end{tabular}


Table 2. Cont.

\begin{tabular}{cc}
\hline Detail Category & Detail Content \\
\hline Operation qualifications & provided by the government \\
Operation platform & developed by the third party \\
Maintenance & provided by the EV manufacturers \\
Vehicle insurance & purchased by LCCS \\
\hline
\end{tabular}

\section{Methods and Data}

Life-cycle break-even analysis can collect information to help ECS companies understand the conditions of making profit. The economic return of the investment on the ECS system depends on the life-cycle operation costs and all possible revenues.

\subsection{Life-Cycle Costs of ECS}

For an accurate prediction and a comprehensive comparison of the two companies, this paper considered all the costs incurred over the lifetime of the ECS. Based on the field investigation and interview, seven categories of life-cycle costs were identified.

\subsubsection{EV Purchase Costs}

Typically, the purchase cost of an ICEV in China is comprised of two main parts: manufacturer suggested retail price and vehicle purchase tax. However, there are two differences between the purchase cost of ICEVs and EVs. (1) In August 2014, the Ministry of Finance (MOF) and the State Administration of Taxation (SAT) issued the Notice on Exemption of Tax on Purchase of New Energy Vehicles, which stipulates that EVs purchased from 1 September 2014 to 31 December 2017 would be exempted from vehicle purchase tax. The deadline for tax exemption was later extended to the end of 2020. (2) To support the development of the EV industry, the Chinese government launched a financial subsidy scheme in January 2009 , followed by several adjustments in the following years. Table 3 presents the evolution of subsidies from 2015 to 2018. The amount of EV purchase subsidies was mainly based on the driving range powered by electricity, and purchasing an EV could result in a large amount of subsidy from both central and local governments.

Based on the above analysis, the purchase cost of an EV can be expressed as:

$$
C_{P C}=C_{M S R P}-C_{G S}
$$

where CPC refers to the purchase cost of an EV, CMSRP refers to manufacturer suggested retail price of an EV, and CGS refers to the government subsidy granted to an EV.

Considering the time to market of different EV models and the comparability of analysis, this paper selected the main EV models of EVCARD and LCCS (Table 4) and the CMSRP and CGS in 2017 for break-even analysis. The related data are detailed in Table 4. After subtracting CPC from CMSRP, the final purchase costs of the five EV models was 134,900, 115,900, 113,800, 123,800, and $97,800 \mathrm{CNY}$, respectively. 
Table 3. EV purchase subsidies of central and local governments from 2015 to 2018 (CNY 10,000 per vehicle).

\begin{tabular}{|c|c|c|c|c|c|c|c|}
\hline \multicolumn{8}{|c|}{ Subsidies in 2015} \\
\hline \multirow[t]{2}{*}{ EV Type } & \multicolumn{6}{|c|}{ Driving Range by Electricity-R (km) } & \multirow[t]{2}{*}{ Source } \\
\hline & $80 \leq \mathrm{R}<150$ & $150 \leq \mathrm{R}<250$ & $R \geq 250$ & & $R \geq 50$ & & \\
\hline $\mathrm{BEV}^{\mathrm{C}}$ & 3.15 & 4.5 & 5.4 & & - & & \\
\hline $\mathrm{PHEV}^{\mathrm{C}}$ & - & - & - & & 3.15 & & MOF et al. [51] \\
\hline $\mathrm{BEV}^{\mathrm{SH}}$ & 4 & 4 & 4 & & - & & SHDRC et al [52] \\
\hline PHEVSH & - & - & - & & 3 & & SHDKC et al. [52] \\
\hline $\mathrm{BEV}^{\mathrm{SZ}}$ & 3.5 & 5 & 6 & & - & & \\
\hline \multirow[t]{2}{*}{ PHEVSZ } & - & - & - & & 3.5 & & SZMPG [53] \\
\hline & \multicolumn{6}{|c|}{ Subsidies in 2016} & \\
\hline \multirow[t]{2}{*}{ EV Type } & \multicolumn{6}{|c|}{ Driving Range by Electricity-R (km) } & Source \\
\hline & $100 \leq \mathrm{R}<150$ & $150 \leq \mathrm{R}<250$ & $R \geq 250$ & & $R \geq 50$ & & \\
\hline $\mathrm{BEV}^{\mathrm{C}}$ & 2.5 & 4.5 & 5.5 & & - & & \\
\hline PHEV $^{\mathrm{C}}$ & - & - & - & & 3 & & MOF et al. [54] \\
\hline $\mathrm{BEV}^{\mathrm{SH}}$ & 1 & 3 & 3 & & - & & \\
\hline PHEV $^{\text {SH }}$ & - & - & - & & 1 & & SHDRC et al. [55] \\
\hline $\mathrm{BEV}^{\mathrm{SZ}}$ & 2.5 & 4.5 & 6 & & - & & SZDRC et al [56] \\
\hline \multirow[t]{2}{*}{ PHEVSZ } & - & - & - & & 3.15 & & SLDKC El di. [OSO] \\
\hline & \multicolumn{6}{|c|}{ Subsidies in 2017} & \\
\hline \multirow[t]{2}{*}{ EV Type } & \multicolumn{6}{|c|}{ Driving Range by Electricity-R (km) } & Source \\
\hline & $100 \leq \mathrm{R}<150$ & $150 \leq \mathrm{R}<250$ & $R \geq 250$ & & $R \geq 50$ & & \\
\hline $\mathrm{BEV}^{\mathrm{C}}$ & 2 & 3.6 & 4.4 & & - & & \\
\hline PHEV $^{\mathrm{C}}$ & - & - & - & & 2.4 & & MUF et al. [54] \\
\hline $\mathrm{BEV}^{\mathrm{SH}}$ & 1 & 1.8 & 2.2 & & - & & SHDRC et al [57] \\
\hline $\mathrm{PHEV}_{\mathrm{SH}}^{\mathrm{SH}}$ & - & - & - & & 1.2 & & SHDike et al. [3/] \\
\hline $\mathrm{BEV}^{\mathrm{SZ}}$ & 1 & 1.8 & 2.2 & & & & \\
\hline \multirow[t]{2}{*}{ PHEV $^{\text {SZ }}$} & - & - & - & & 1.2 & & SZDRC [58] \\
\hline & \multicolumn{6}{|c|}{ Subsidies in 2018} & \\
\hline \multirow[t]{2}{*}{ EV Type } & \multicolumn{6}{|c|}{ Driving range by electricity-R (km) } & Source \\
\hline & $100 \leq R<150$ & $150 \leq R<250$ & $R \geq 250$ & $300 \leq \mathrm{R}<400$ & $R \geq 400$ & $R \geq 50$ & \\
\hline $\mathrm{BEV}^{\mathrm{C}}$ & 1.5 & 2.4 & 3.4 & 4.5 & 5 & - & \\
\hline $\mathrm{PHEV}^{\mathrm{C}}$ & - & - & - & - & - & 2.2 & MUF et al. [59] \\
\hline $\mathrm{BEV}^{\mathrm{SH}}$ & 0.75 & 1.2 & 1.7 & 2.25 & 2.5 & - & \\
\hline PHEV $^{\text {SH }}$ & - & - & - & - & - & 0.66 & SHDRC et al. [60] \\
\hline${ }^{*} \mathrm{BEV}^{\mathrm{SZ}}$ & $0.75 / 0.525 / 0.375$ & $1.2 / 0.84 / 0.6$ & $1.7 / 1.19 / 0.85$ & 2.25/1.575/1.125 & $2.5 / 1.75 / 1.25$ & 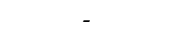 & \\
\hline $\mathrm{PHEV}^{\mathrm{SZ}}$ & - & - & - & - & - & $0.66 / 0.462 / 0.33$ & SZDRC [b1] \\
\hline
\end{tabular}

Note: $\mathrm{BEV}$ is the abbreviation of battery electric vehicle, PHEV is the abbreviation of plug-in hybrid electric vehicle. Superscript C represents central government, Superscript SH represents Shanghai government, Superscript SZ represents Shenzhen government. *: Financial subsidy of Shenzhen government in 2018 was divided into three phases: 1 January to 11 February, 12 February to 11 June, 12 June to 31 December, with a gradual decreasing trend. 
Table 4. Purchase costs of the five EV models (unit: 10,000 CNY).

\begin{tabular}{cccccc}
\hline & R-km & C $_{\text {MSRP }}$ & C $_{\mathbf{G S}}$ & $\mathbf{C}_{\mathbf{P C}}$ & Source \\
\hline Roeway E50 & 170 & 18.89 & 5.4 & 13.49 & MIIT and SAT [62] \\
Chery eQ & 151 & 16.99 & 5.4 & 11.59 & MIIT and SAT [63] \\
JAC IEV5 & 252 & 17.98 & 6.6 & 11.38 & MIIT and SAT [64] \\
BAIC EV160 & 150 & 17.78 & 5.4 & 12.38 & MIIT and SAT [65] \\
Geely ZD D2 & 152 & 15.18 & 5.4 & 9.78 & MIIT and SAT [66] \\
\hline
\end{tabular}

\subsubsection{EV Insurance Costs}

Insurance cost refers to the cost incurred when the operators insure the vehicles. To calculate the EV insurance cost, it was necessary to clarify the insurance categories and insurance contract characteristics. However, the government has not yet defined the specific categories of EV insurance, since EV is still in its infancy. Through the investigation of EVCARD and LCCS, it was assumed that the insurance categories of EVs were basically the same as those of ICEVs, and the contract still adopted the traditional lump-sum insurance premium. The specific insurance categories and their cost are shown in Table 5.

Table 5. Insurance categories and cost of EVs.

\begin{tabular}{cc}
\hline Category & Cost (CNY per Vehicle per Year) \\
\hline Compulsory traffic insurance $\left(I_{C I}\right)$ & 950 (seating capacity $<6 ; 1100$ (seating capacity $\geq 6)$ \\
Loss liability insurance $\left(I_{L I}\right)$ & basic premium $\left(I_{B P}\right)+C_{M S R P} \times 1.0880 \%$ \\
Commercial third-party insurance $\left(I_{T I}\right)$ & 1252 (amount of compensation equals 0.5 million CNY) \\
“Non-deductible" insurance $\left(I_{D I}\right)$ & $\left(I_{L I+} I_{T I}\right) \times 20 \%$ \\
Vehicle personnel liability insurance $\left(I_{P I}\right)$ & 50 (per seat) \\
\hline
\end{tabular}

Thus, the insurance cost of an EV per year can be expressed as:

$$
C_{I C}=I_{C I}+I_{L I}+I_{T I}+I_{D I}+I_{P I}=I_{C I}+\left(I_{B P}+C_{M S R P} \times 1.0880 \%\right)+I_{T I}+\left[\left(I_{L I+} I_{T I}\right) \times 20 \%\right]+50 \times N_{S E A T}
$$

where $C_{I C}$ refers to the insurance cost of an EV per year, $I_{B P}=460$, and $N_{S E A T}$ means the seating capacity of an EV; the meanings of other variables in the Equation (2) are shown in Table 5. Based on Equation (2), the annual insurance costs of the five EV models were obtained, as shown in Table 6.

Table 6. Insurance costs of the five EV models (CNY per vehicle per year).

\begin{tabular}{cccccccc}
\hline & Seating Capacity & $\boldsymbol{I}_{\boldsymbol{C I}}$ & $\boldsymbol{I}_{\boldsymbol{L I}}$ & $\boldsymbol{I}_{\boldsymbol{T I}}$ & $\boldsymbol{I}_{\boldsymbol{D I}}$ & $\boldsymbol{I}_{\boldsymbol{P I}}$ & $\boldsymbol{C}_{\boldsymbol{I C}}$ \\
\hline Roeway E50 & 5 & 950 & 2525 & 1252 & 753 & 250 & 5730 \\
Chery eQ & 5 & 950 & 2309 & 1252 & 712 & 250 & 5473 \\
JAC IEV5 & 5 & 950 & 2416 & 1252 & 734 & 250 & 5602 \\
BAIC EV160 & 5 & 950 & 2394 & 1252 & 729 & 250 & 5575 \\
Geely ZD D2 & 5 & 950 & 2112 & 1252 & 673 & 250 & 5237 \\
\hline
\end{tabular}

\subsubsection{Parking Spot Costs}

In order to calculate the parking spot costs $\left(C_{P S C}\right)$ of ECS companies, two steps were followed: firstly, the parking spot rental of an EV was studied; secondly, the number ratio of parking spots to vehicles was defined. Typically, the rent of a parking spot is influenced by its location and traffic flow of the location. Usually the rent is much higher in the areas with large traffic, such as shopping malls and supermarkets in urban areas, where the rent is generally around CNY 1200 per month for a parking spot. The rent of areas with less traffic in suburbs is generally around CNY 200-300 per month for a parking spot. In the business operation process, ECS companies can reduce parking spot costs 
through business cooperation with commercial real estate companies or property companies, as we described above.

In the one-way ECS system, there are no restrictions on the drop-off stations, which would definitely result in the imbalance of EVs between stations [67]. The number of EVs parked at some stations may exceed the number of the EVs originally allocated. Therefore, the number of parking spots in an ECS system is usually required to be larger than the number of EVs. Thus, the annual parking spot cost of an EV can be expressed as:

$$
C_{P S C}=\alpha \times P_{\text {space }}
$$

where $C_{P S C}$ is the parking spot cost of a shared EV per year, $P_{\text {space }}$ is the rental of a parking spot of a shared EV per year, and $\alpha$ is the number ratio of parking spots to EVs.

Through a field survey, the rent of a parking spot for each EV model and the value of $\alpha$ were obtained, as shown in Table 7. The parking spot rent for ZD D2 was the lowest, because its body was the smallest and it occupied the least space. The total parking spot costs of EVCARD was much lower than that of the LCCS, because many parking spots of EVCARD were cooperative with universities or businesses.

Table 7. Parking spot costs of the five EV models (CNY per vehicle per year).

\begin{tabular}{ccccc}
\hline EV Model & $\boldsymbol{P}_{\text {space }}$ & $\alpha$ & Location & $\boldsymbol{C}_{P S C}$ \\
\hline Roeway E50 & 3600 & \multirow{2}{*}{1.5} & Shanghai & 5400 \\
Chery eQ & 3600 & & & 5400 \\
JAC IEV5 & 7200 & & & 10,800 \\
BAIC EV160 & 7200 & \multirow{2}{*}{1.5} & Shenzhen & 10,800 \\
Geely ZD D2 & 3000 & & & 4500 \\
\hline
\end{tabular}

\subsubsection{Costs of Charging Piles}

The costs of charging piles for ECS companies involves the costs of procurement, installation, and maintenance. To calculate the final cost of a charging pile of an EV per year, four assumptions need to be defined: market price of a charging pile, residual value rate, depreciation period, and number ratio of parking spots to charging piles. The specific calculation method is as follows:

$$
C_{C P C}=\frac{\beta \times P_{\text {pile }} \times\left(1-r_{c}\right)}{N_{c}}
$$

where $C_{C P C}$ means the charging pile costs shared by an EV per year, $\beta$ means the number ratio of charging piles to EVs in the ECS system, $P_{\text {pile }}$ means the market price of a charging pile, including procurement, installation, and maintenance, $r_{c}$ means the residual value rate of a charging pile, and $N_{c}$ means the depreciation period of a charging pile.

Typically, charging piles are mainly divided into two categories: AC charging piles and DC charging piles. A $45 \mathrm{~kW}$ DC charging pile costs between CNY 100,000 and CNY 150,000 in China, while a $7 \mathrm{~kW}$ AC charging pile costs between CNY 4000 and CNY 7000. As for the installation cost, a DC charging pile is about CNY 30,000, and an AC charging pile is about CNY 6000. The charging piles of both EVCARD and LCCS are AC charging piles. Thus, the market price of a charging pile was estimated to be approximately CNY 10,000 in this research. Based on the authors' investigation, the residual value rate was about $5 \%$, and a 8-year depreciation period was adopted. It was assumed that each parking spot was equipped with a charging pile; thus the value of $\beta$ equaled 1.5. Based on the above analysis, the final charging pile costs shared by an EV was estimated around CNY 1781 per year. 


\subsubsection{Energy Costs}

Energy costs refers to the electricity costs incurred when the shared EVs are stationed to connected to the charger for recharging. Specifically, the energy costs of an EV per year $\left(C_{E C}\right)$ are related to four factors: average daily mileage $(D M)$, energy consumption ratio of an EV $(E C R)$, price of electricity $\left(P_{e}\right)$, and charging efficiency $(\eta)$, which can be expressed in Equation (5).

$$
C_{E C}=E C R \times \frac{D M}{\eta} \times P_{e} \times 365
$$

In July 2014, the Notice on the Electricity Price of Electric Vehicles issued by NDRC [68] stipulated that the electricity price of charging facilities in government organizations, enterprises, institutions, and public parking lots belonged to the category of general industry and commerce [69]. Thus, the ECS companies paid the general commercial rate (including VAT) for electricity, and the data were gathered from local government documents. In Shanghai, the general commercial rate for electricity is CNY 0.969 per kWh during the peak time (06:00-22:00) and CNY 0.441 per kWh during the valley time (22:00-06:00). In Shenzhen, the price is CNY 0.9966 per kWh during the peak time (09:00-11:30, 14:00-16:30, 19:00-21:00), CNY 0.7365 per kWh during the flat time (07:00-09:00, 11:30-14:00, 16:30-19:00, 21:00-23:00), and CNY 0.2163 per $\mathrm{kWh}$ during the valley time (23:00-07:00). This paper used the average price of peak, flat, and valley time for calculation, as shown in Table 8.

Table 8. Energy costs of the five EV models (CNY per vehicle per year).

\begin{tabular}{cccccc}
\hline & ECR- $\mathbf{k W h} / \mathbf{k m}$ & $\mathbf{D M}-\mathbf{k m}$ & $\boldsymbol{\eta}$ & $\mathbf{P e}-\mathbf{C N Y} / \mathbf{k W h}$ & $\mathbf{C}_{\mathrm{EC}}-\mathbf{C N Y}$ \\
\hline Roeway E50 & 0.133 & $2 x / 3$ & $80 \%$ & 0.705 & $28.5 x$ \\
Chery eQ & 0.112 & $2 x / 3$ & $80 \%$ & 0.705 & $24 x$ \\
JAC IEV5 & 0.115 & $2 x / 3$ & $80 \%$ & 0.6498 & $22.7 x$ \\
BAIC EV160 & 0.159 & $2 x / 3$ & $80 \%$ & 0.6498 & $31.4 x$ \\
Geely ZD D2 & 0.121 & $2 x / 3$ & $80 \%$ & 0.6498 & $23.9 x$ \\
\hline
\end{tabular}

The charging efficiency was obtained from the study of Zhu et al. [69], and one of the authors of the study is Ming-Gao Ouyang, who is an academician of the Chinese Academy of Sciences and an expert in automotive power systems.

The average daily mileage depends on the average minutes that a share EV is rented each day. It was assumed that a shared EV is always in operation when it is rented. Then, it can be calculated through the following equation:

$$
D M=\frac{x}{60} \times \text { Speed }
$$

where $x$ denotes the total minutes of a shared EV rented in one day (minute per day), Speed refers to the average driving speed of a shared EV. According to the Report on Urban Transportation in the First Quarter of 2018 issued by Didi Company [70], the average speed of cars in Shanghai and Shenzhen is $39.07 \mathrm{~km} / \mathrm{h}$ and $40.2 \mathrm{~km} / \mathrm{h}$, respectively. For convenience of calculation, we set the value of Speed as $40 \mathrm{~km} / \mathrm{h}$. The data and calculation results are shown in Table 8.

\subsubsection{Maintenance Cost}

EVs usually have much less maintenance cost than ICEVs due to the different of power systems. Moreover, EV manufacturers are responsible for quality assurance of the core parts including batteries, motors, and electric systems in China. In April 2015, MOF, MIIT, NDRC, and MST jointly issued the Notice on the Financial Support Policy for the Promotion and Application of New Energy Vehicles in 2016-2020, which stipulated that electric passenger car manufacturers should provide quality assurance 
for no less than 8 years or 120,000 km. Thus, the maintenance cost for ECS companies are relatively low. Its calculation is expressed in Equation (7).

$$
C_{M C}=P_{\mathrm{m}} \times D M \times 365
$$

where $C_{M C}$ represents the maintenance cost of an EV per year; $P_{m}$ represents the life-cycle maintenance cost of an EV per $\mathrm{km}$, and its value is estimated as CNY 0.0616 per $\mathrm{km}$ referring to the discussion in Zhao [71]; and DM has the same meaning in Equation (5). The calculation results are presented in Table 9.

Table 9. Maintenance costs of the five EV models (CNY per vehicle per year).

\begin{tabular}{cccc}
\hline & $\mathbf{P}_{\mathbf{m}-\mathrm{CNY} / \mathbf{k m}}$ & $\mathbf{D M}-\mathbf{k m}$ & $\mathbf{C}_{\mathbf{M C}}-\mathbf{C N Y}$ \\
\hline Roeway E50 & 0.0616 & $2 x / 3$ & $15 x$ \\
Chery eQ & 0.0616 & $2 x / 3$ & $15 x$ \\
JAC IEV5 & 0.0616 & $2 x / 3$ & $15 x$ \\
BAIC EV160 & 0.0616 & $2 x / 3$ & $15 x$ \\
Geely ZD D2 & 0.0616 & $2 x / 3$ & $15 x$ \\
\hline
\end{tabular}

\subsubsection{Operational Costs}

Operational costs mainly included labor costs, marketing costs, digital platform costs, and other operational miscellaneous costs in this research.

The labor costs included the costs related to administrative personnel, platform operators, customer service personnel, EV relocation personnel, EV cleaners, etc. According to the survey, each personnel could supervise 10 shared EVs and his/her average wage was determined to be approximately CNY 100,000 per year. As indicated in the above analysis, 8000 shared EVs of EVCARD are in operation in Shanghai and 3000 shared EVs of LCCS are in operation in Shenzhen. Consequently, a total of 800 employees and 300 employees are required for EVCARD and LCCS, respectively, and the labor costs of EVCARD and LCCS are CNY 80 million and CNY 30 million per year respectively.

The marketing cost mainly refers to the cost incurred by media propaganda such as internet and TV advertisement, which was estimated at CNY 50,000 per month. Thus, the annual marketing cost is about CNY 600,000.

The digital platform costs include the initial purchase cost, daily maintenance cost, and platform upgrade cost. Typically, the initial platform purchase payment is made in annual instalments rather than in one lump sum. Therefore, the digital platform costs were regarded as annual expenditure costs for calculation in this research. According to the survey, annual platform cost of EVCARD was around CNY 9.6 million, and that of LCSS was around CNY 1.2 million.

Other operational miscellaneous costs mainly refer to the rental of office space, daily office expenses, etc. According to the survey, we estimated the annual costs at CNY 600,000.

Based on the above analysis, the annual operational costs were found to be CNY 90.8 million for EVCARD and CNY 32.4 million for LCCS in total. Consequently, the operational cost per vehicle per year $\left(C_{O C}\right)$ was determined to be CNY 11,350 for EVCARD and CNY 10,800 for LCCS.

\subsection{Benefits of ECS System}

Typically, there are three main sources of revenue for ECS companies in China: EV rental revenue, EV residual revenue, and advertising revenue.

\subsubsection{EV Rental Revenue}

In China, most ECS companies, including EVCARD and LCSS, collect rent from EVs according to user driving time, and only a few companies adopt the charging method based on the integration 
of driving time and mileage. Therefore, this paper calculated the rental revenue on the basis of the driving time, as shown in Equation (8).

$$
R_{R R}=(A x+B) \times 365
$$

where $R_{R R}$ represents the rental revenue of a shared EV per year, $A$ represents the unit price of renting a shared EV (CNY per minute), $B$ represents the other costs for users to rent a shared EV (CNY per minute), and $x$ denotes the total minutes a shared EV is rented for in one day (minute per day).

As shown in Table 10, users renting a Roeway E50 or Chery eQ from EVCARD needed to pay CNY 0.6 per min, which included basic rental (CNY 0.5 per minute) and urban service fee (CNY 0.1 per min). The maximum rental of an EV was CNY 180 for a whole day. In addition to the above fees, an additional charge, namely a non-deductible insurance fee, was required for each EV rental order from EVCARD. In order to simplify the calculation, this paper assumed that the non-deductible insurance fee was CNY 8 per vehicle per day. For LCCS, however, it only charged the basic rent and no extra premium, as shown in Table 10.

Table 10. Rental revenue of the five EV models (CNY per vehicle per year).

\begin{tabular}{ccccc}
\hline & A (CNY/Minute) & B (CNY/day) & Max (Ax)-CNY/day) & R $_{\mathbf{R R}}(\mathbf{C N Y})$ \\
\hline Roeway E50 & 0.6 & 8 & 180 & $219 x+2920$ \\
Chery eQ & 0.6 & 8 & 180 & $219 x+2920$ \\
JAC IEV5 & 0.5 & 0 & 150 & $183 x$ \\
BAIC EV160 & 0.4 & 0 & 120 & $146 x$ \\
Geely ZD D2 & 0.3 & 0 & 118 & $110 x$ \\
\hline
\end{tabular}

\subsubsection{EV Residual Value Revenue}

Vehicle residual value refers to the remaining usage value within the prescribed reasonable service life of the vehicle. For a shared EV, its residual value is greatly affected by the battery, because the battery cost accounts for a large part of the total cost of EVs, and the battery capacity will be gradually reduced with the increase of the number of charges and discharges, which leads to the low residual value of EVs. Therefore, the residual values of the power battery system and other parts of the EV were calculated separately in this research.

Drawing on the study of Ruan and Cao [72] about the residual value of a traditional gasoline taxi, the residual value of a shared EV in this research was calculated using Equation (9).

$$
R_{R V}=\lambda^{N} \times C_{P C} \times(1-\theta)+C_{P C} \times \theta-\left(\delta_{1}+\delta_{2}\right) \times D M \times 365 \times N
$$

where $R_{R V}$ represents the residual value of a shared $\mathrm{EV}, \lambda$ represents the annual depreciation rate of a shared $\mathrm{EV}, N$ represents the service lifespan of a shared $\mathrm{EV}, \theta$ is cost ratio of battery to the whole vehicle, $\delta_{1}$ refers to the depreciation value of an ICEV per $\mathrm{km}$, and $\delta_{2}$ refers to the depreciation value of a battery per $\mathrm{km}$.

According to [72], the annual depreciation rate of a traditional gasoline taxi is $75 \%$ and the depreciation value of an ICEV is CNY 0.1954 per $\mathrm{km}$. Thus, we set the value of $\lambda$ as $70 \%$ considering the difference in operating time between shared cars and taxis; the value of $\delta_{1}$ was set as 0.1954 , as shown in Table 11. According to the study of Sun et al. [73], the battery cost currently accounts for about $40-50 \%$ of the total cost of EV in China, the number of battery charge-discharge cycles is about 2000, and the unit capacity cost of a battery is estimated to be CNY 1700/kWh. Thus, this research set the value of $\theta$ as $40 \%$ and $\delta_{2}$ as CNY 0.127 per $\mathrm{km}$, as shown in Table 11. 
Table 11. Residual value revenue of the five EV models (CNY per vehicle per year).

\begin{tabular}{cccccccc}
\hline & $\boldsymbol{\lambda}$ & $\begin{array}{c}\mathbf{C}_{\mathbf{P C}} \mathbf{( 1 0 , 0 0 0} \\
\mathbf{C N Y}\end{array}$ & $\boldsymbol{\theta}$ & $\boldsymbol{\delta}_{\mathbf{1}}(\mathbf{C N Y} / \mathbf{k m})$ & $\boldsymbol{\delta}_{\mathbf{2}}(\mathbf{C N Y} / \mathbf{k m})$ & $\mathbf{D M}(\mathbf{k m})$ & $\mathbf{R}_{\mathbf{R V}}(\mathbf{C N Y})$ \\
\hline Roeway E50 & 0.7 & 13.49 & $40 \%$ & 0.1954 & 0.127 & $2 x / 3$ & $0.7^{\mathrm{N}} \times 80,904+53,960-78.5 x \mathrm{~N}$ \\
Chery eQ & 0.7 & 11.59 & $40 \%$ & 0.1954 & 0.127 & $2 x / 3$ & $0.7^{\mathrm{N}} \times 69,540+46,360-78.5 x \mathrm{~N}$ \\
JAC IEV5 & 0.7 & 11.38 & $40 \%$ & 0.1954 & 0.127 & $2 x / 3$ & $0.7^{\mathrm{N}} \times 68,280+45,520-78.5 x \mathrm{~N}$ \\
BAIC EV160 & 0.7 & 12.38 & $40 \%$ & 0.1954 & 0.127 & $2 x / 3$ & $0.7^{\mathrm{N}} \times 74,280+49,520-78.5 x \mathrm{~N}$ \\
Geely ZD D2 & 0.7 & 9.78 & $40 \%$ & 0.1954 & 0.127 & $2 x / 3$ & $0.7^{\mathrm{N}} \times 58,680+39,120-78.5 x \mathrm{~N}$ \\
\hline
\end{tabular}

\subsubsection{Non-Rental Revenue}

Apart from the rental revenue, advertising revenue is another relatively stable revenue source for Chinese ECS companies. However, this part of the revenue is relatively small at present. Based on the survey, the average advertising revenue per EV $\left(R_{A R}\right)$ was determined to be CNY 1300 a year.

\subsection{Calculation Method}

In this research, the break-even moment a shared EV needs to be rented for per day was calculated, i.e., calculating the value of $x$ for the five EV models. This break-even analysis was conducted by summing the life-cycle costs and revenue of each shared EV for ECS companies over the EV service lifespan. Then, each sum was converted into the present value (PV) by using a discount rate. Finally, the net present value (NPV) was set as zero to get the break-even moment.

\subsubsection{Period of Use}

The service life of a shared EV is regulated by its total travel distance and battery life. Several studies about the useful lifespan of a lithium-ion battery were reviewed. Wang et al. [74] estimated that the battery life is about 5.5 years if EVs are used only for driving without offering V2G grid services. $\mathrm{Xu}$ et al. [75] constructed an empirical model and estimated a battery life of 6.8 years. However, there is no relevant research on the service life of a shared EV in China.

Professor Fu of Tongji University (Research Center for New Energy Vehicle Industrialization, School of Automobile) said, "typically, three years is a commonly accepted service life of shared EVs in this industry". In August 2016, Ming-Gao Ouyang pointed out at the China Electric Vehicle Hundred People's Congress Forum that battery of EVs can support about 200,000-300,000 kilometers of driving during the lifetime. (The China Electric Vehicle 100 People's Congress is the most authoritative and influential organization about EVs in China. It was jointly launched by government officials, scholars, and entrepreneurs in May 2014.) Thus, this paper considers the break-even analysis of the five EV models throughout the lifespan of three years after which they are left with some vehicle residual value.

\subsubsection{Discount Rate}

The discount rate refers to the interest rate used to change future payments to present values, which considers the value change of money over time, and evaluates the opportunity cost of an investment [37]. For the calculation in this study, the discount rate was set as $10 \%$ by drawing on the study of Xue et al. [76].

\subsubsection{Break-Even Analysis Model}

The PV of each EV's life-cycle costs over the service lifespan is expressed as Equation (10).

$$
P V_{C}=C_{P C}+C_{C P C} \times N+\sum_{t=1}^{N} \frac{C_{I C}+C_{P S C}+C_{E C}+C_{M C}+C_{O C}}{(1+r)^{t}}
$$

where $P V_{C}$ is the present value of the life-cycle costs of a shared $\mathrm{EV}, r$ is the discount rate, and $N$ is the service lifespan of a shared EV, as shown in Equation (8). 
In order to calculate the life-cycle costs, the purchase cost of EVs and charging piles are summed together with other yearly costs including insurance cost, parking spot cost, energy cost, maintenance cost, and operational cost, as shown in Equation (9). Two points are worth noting: (1) The purchase cost of EVs and charging piles are one-time costs in the year of acquisition of EVs and installation of charging piles. ECS companies must complete the purchase and installation before they are officially operated. Therefore, the $P V$ calculation is not applied to these two types of costs. (2) $C_{C P C}$ represents annual charging pile costs shared by each EV during the depreciation period, as described in Section 3.1.4. Therefore, the value of $C_{C P C}$ needs to be multiplied by the lifespan of the EV service.

Accordingly, the $P V$ of the revenue that a shared EV can bring about over the service lifespan is expressed as Equation (11).

$$
P V_{R}=\frac{R_{R V}}{(1+r)^{N}}+\sum_{t=1}^{N} \frac{R_{A R}+R_{R R}}{(1+r)^{t}}
$$

where $P V_{R}$ is the present value of the revenue of a shared EV.

Thus, the break-even moment a shared EV needs to be rented for per day can be obtained through Equation (12), with which the PV of the ECS company's revenue equals the $P V$ of the ECS company's life-cycle costs, i.e., when the NPV of the ECS company equals zero.

$$
N P V=P V_{R}-P V_{C}=0 \frac{R_{R V}}{(1+r)^{N}}+\sum_{t=1}^{N} \frac{R_{A R}+R_{R R}}{(1+r)^{t}}-C_{P C}-C_{C P C} \times N-\sum_{t=1}^{N} \frac{C_{I C}+C_{P S C}+C_{E C}+C_{M C}+C_{O C}}{(1+r)^{t}}=0
$$

\section{Results and Sensitivity Analysis}

\subsection{Calculation Results}

Ultimately, with all the data and parameters defined above, the calculation results of the break-even moment are shown in Figures 3 and 4. The main result that can be extracted from the comparison between Figures 3 and 4 is that the break-even moment for LCCS's EV models was much longer than that of EVCARD's EV models. For EVCARD, a shared Roeway E50 must be in operation for at least $3.38 \mathrm{~h}$, i.e., $202.6 \mathrm{~min}$ a day, to reach the break-even moment, and a Chery eQ must be in operation for about $3 \mathrm{~h}$ (181.3 $\mathrm{min})$ to reach the break-even moment. However, a shared JAC IEV5 must run for about $4 \mathrm{~h}(244.8 \mathrm{~min})$ a day. A shared BAIC EV160 and Geely ZD D2 must be in operation for over $5.4 \mathrm{~h}$ (323 $\mathrm{min})$ and $5 \mathrm{~h}$ (301 $\mathrm{min})$ a day to make a profit.

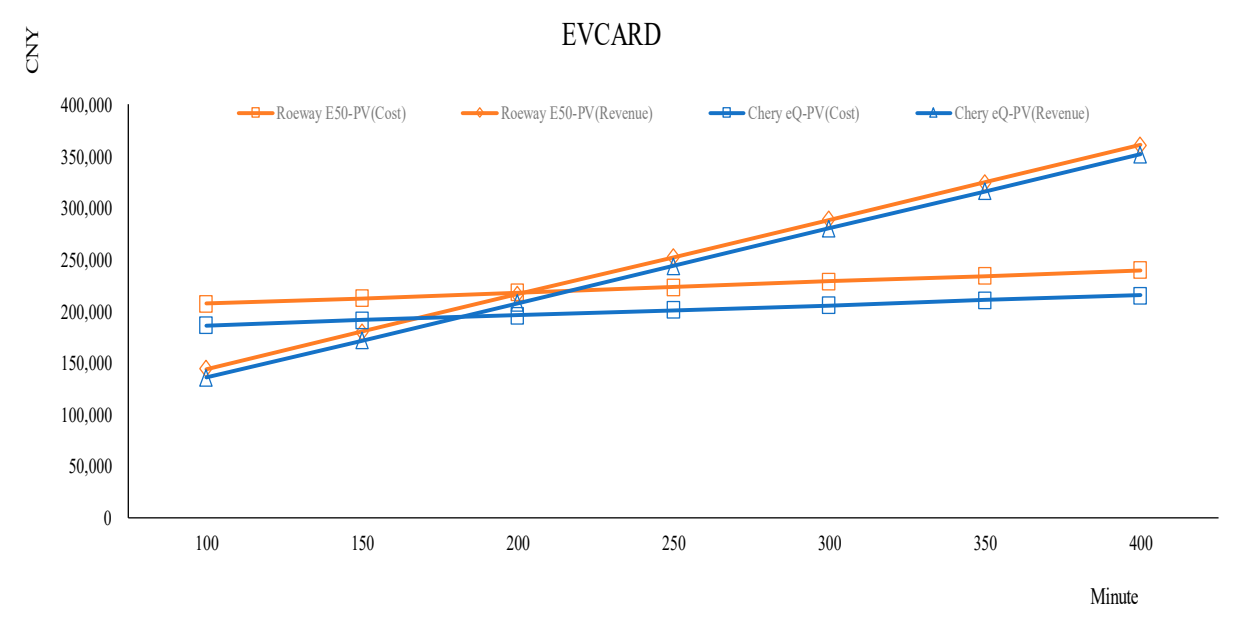

Figure 3. Break-even moment of Roeway E50 and Chery eQ. 


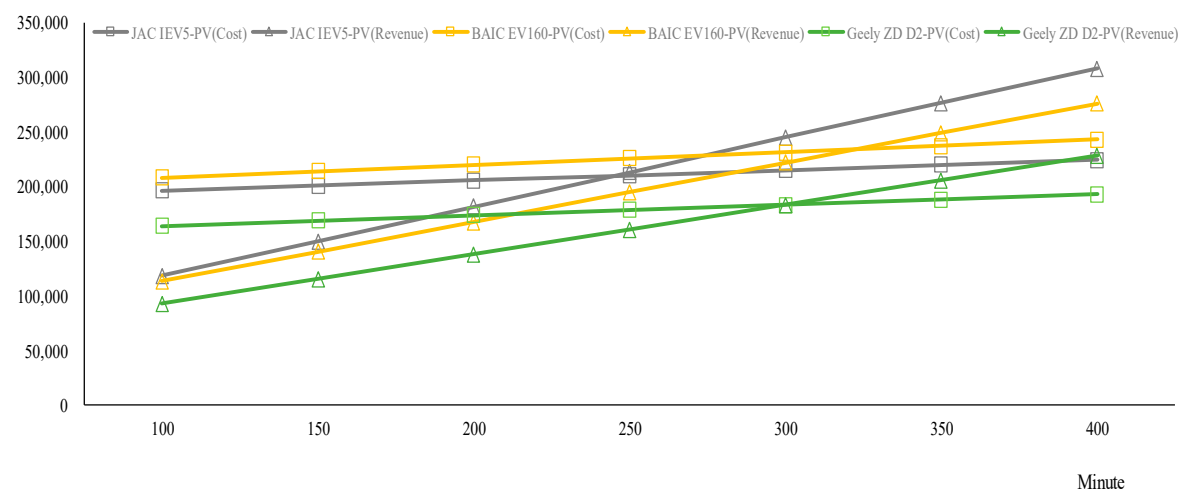

Figure 4. Break-even moment of JAC IEV5, BAIC EV160 and Geely ZD D2.

\subsection{Sensitivity Analysis}

The above calculation results were constrained to specific values and some assumptions. In order to investigate the effect of key variables on the break-even moment and reduce the impact of uncertainty in specific values and assumptions on the calculation results, a sensitivity analysis was needed.

The manufacturer suggested retail price $\left(C_{M S R P}\right)$, government subsidy $\left(C_{G S}\right)$, rent of a parking spot per year $\left(P_{\text {space }}\right)$, market price of a charging pile $\left(P_{\text {pile }}\right)$, price of electricity $\left(P_{e}\right)$, operational cost $\left(C_{O C}\right)$, unit rental price $(A)$, and non-rental revenue $\left(R_{A R}\right)$ were the variables set to vary according to its future possible trend (Table 12). The different value ranges of variation for each variable were tested in the sensitivity analysis, while the values of other variables remained at their original values adopted in the above break-even analysis. The results of sensitivity analysis for each variable are discussed below.

Table 12. Variation range of the variables in sensitivity analysis.

\begin{tabular}{ccc}
\hline Variable & Base Value & Variation Range \\
\hline$C_{\text {MSRP }}$ & shown in Table & decrease by $10 \%, 15 \%, 20 \%, 25 \%, 30 \%$ \\
$C_{G S}$ & shown in Table 4 & decrease by $30 \%, 50 \%, 70 \%, 90 \%, 100 \%$ \\
$P_{\text {space }}$ & shown in Table 7 & decrease by $10 \%, 20 \%, 30 \%$ and increase by $10 \%, 20 \%$ \\
$P_{\text {pile }}$ & 10,000 CNY & decrease by $10 \%, 15 \%, 20 \%, 25 \%, 30 \%$ \\
$P_{e}$ & shown in Table 7 & decrease by $10 \%, 15 \%, 20 \%, 25 \%, 30 \%$ \\
$C_{O C}$ & shown in Section 3.1 .7 & decrease by $10 \%, 20 \%, 30 \%$ and increase by $10 \%, 20 \%$ \\
$A$ & shown in Table 10 & increase by $10 \%, 15 \%, 20 \%, 25 \%, 30 \%$ \\
$R_{A R}$ & 1300 CNY & increase by $30 \%, 50 \%, 70 \%, 90 \%, 100 \%$ \\
\hline
\end{tabular}

\subsubsection{Sensitivity Analysis of $\mathrm{C}_{\mathrm{MSRP}}$}

The first variable is the manufacturer suggested retail price. The values used in the above break-even analysis were all over CNY 150,000 for the five EV models. However, the retail price is likely to decrease with the technology improvement of battery and mass production. The Economic and Technological Research Institute of China Petroleum Corporation predicated that the cost of power batteries of EVs in China will gradually decrease from CNY 1700/kWh in 2017 to CNY 700/kWh in 2030 [77]. Thus, $C_{M S R P}$ was assumed to decrease the base value by $10 \%$ to $30 \%$. Figure 5 shows the sensitivity results, which indicated that the two EV models of EVCARD were more sensitive to the decreasing prices than those of LCCS. Specifically, the break-even moment of the Roeway E50 was the most sensitive among the five models, which will drop by $45.6 \%$ with $C_{M S R P}$ falling by $30 \%$. The break-even moment of Chery eQ was still the least among the five models, which is only $1.7 \mathrm{~h}$ if $C_{\text {MSRP }}$ decreases by $30 \%$. 


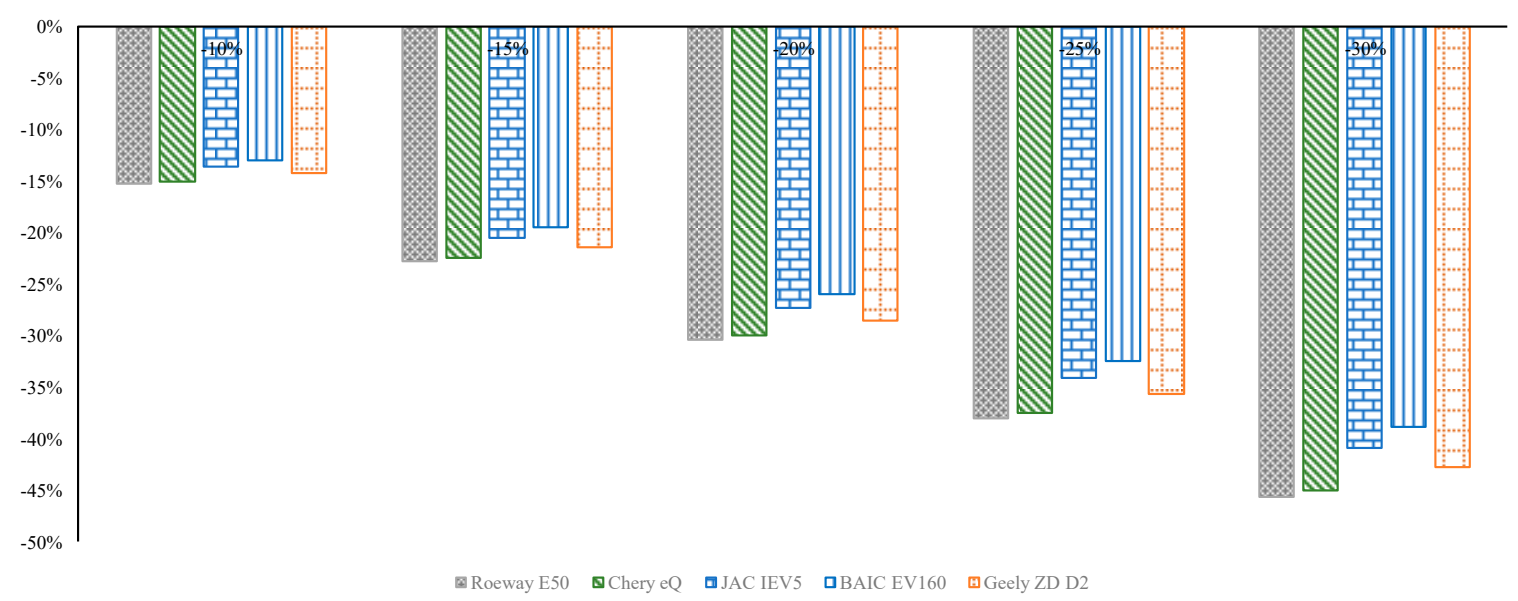

Figure 5. Sensitivity analysis of manufacturer suggested retail price on break-even moment.

\subsubsection{Sensitivity Analysis of $C_{G S}$}

The second variable is the government subsidy. As elaborated earlier, government subsidy is critical for reducing the purchase price and enhancing the attraction of EVs. However, the EV purchase subsidy scheme implements the mechanism of gradual reduction, as evidenced in Table 3 , and this scheme will be finally abolished in 2020 [78]. Thus, $C_{G S}$ was assumed to decrease the base value by $30 \%$ to $100 \%$ in this paper. The sensitivity results (Figure 6) showed that the response range of their break-even moments varied from $15 \%$ to $50 \%$ when the government subsidy decreased by $30 \%$ to $100 \%$. The JAC IEV5 and Geely ZD D2 of LCCS were more sensitive to the decreasing government subsidy than the Roeway E50 and Chery eQ of EVCARD. If the government subsidy is repealed, LCCS's profitability will face great challenges. BAIC EV160 and Geely ZD D2 must be in operation for more than $7.5 \mathrm{~h}$ a day to make a profit.

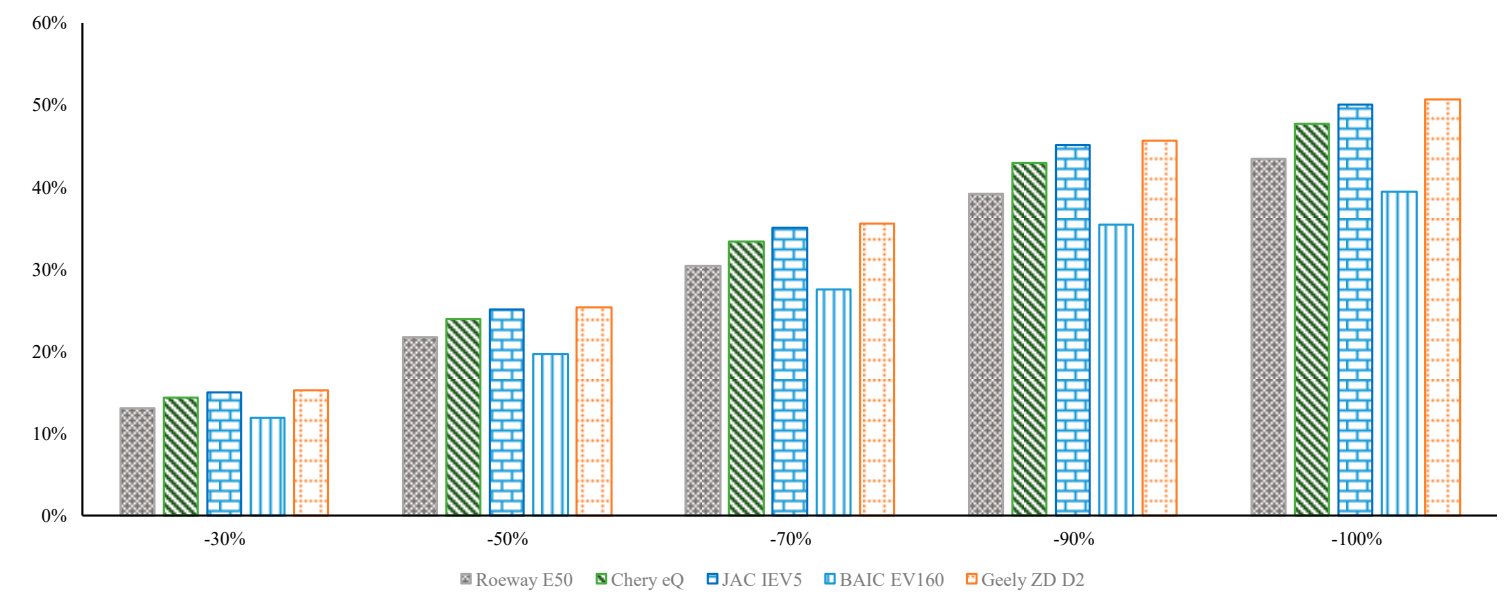

Figure 6. Sensitivity analysis of government subsidy on break-even moment.

\subsubsection{Sensitivity Analysis of $P_{\text {space }}$}

The third variable is the rental cost of a parking spot per year. The change of this variable is affected by many factors, including government policies, partnership networks, and urban land rent. In the early stage of the development of an ECS, some local governments tend to provide free rental parks for ECS companies to stimulate their enthusiasm for participation. However, these preferential policies are gradually abolished in the later stages. Meanwhile, the partnership network may continue to expand with the development of the ECS and the business cooperation between the partners may be conducive to the reduction of rents. Thus, $P_{\text {space }}$ was assumed to vary from $-30 \%$ to $20 \%$. Figure 7 
shows the sensitivity results. Obviously, the five models were less sensitive to the change of parking spot rental. The most sensitive model was JAC IEV5; however, it break-even moment only ranged from a maximum decline rate of $10.19 \%$ to a minimum increase rate of $6.12 \%$ in the sensitivity analysis.

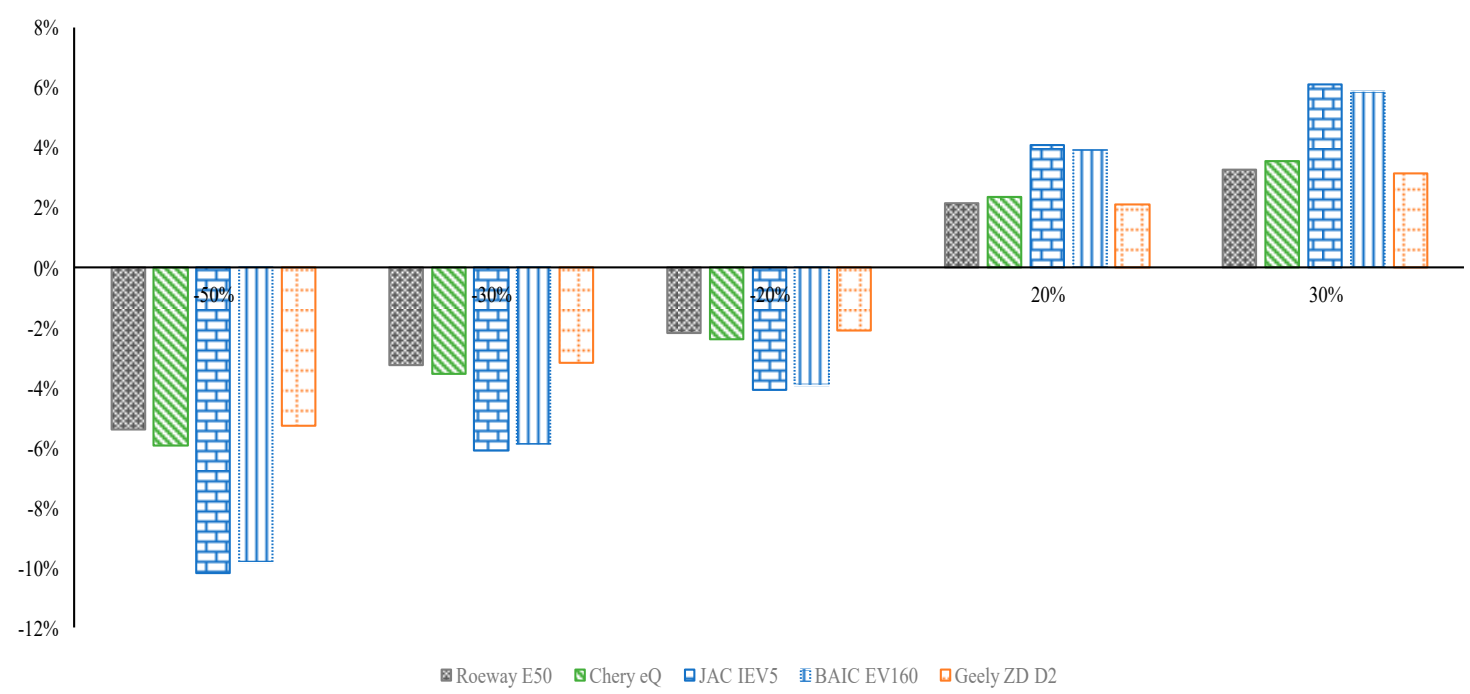

Figure 7. Sensitivity analysis of rental cost of parking spots on break-even moment.

\subsubsection{Sensitivity Analysis of $P_{\text {pile }}$}

The fourth variable is the market price of a charging pile. Like the purchase price of EVs, $P_{\text {pile }}$ was also assumed to decrease the base value by $10 \%$ to $30 \%$, considering the future development of technology. Figure 8 shows the sensitivity results, which indicated that the sensitivity of the five EV models to this variable was extremely low. When the market price of a charging pile dropped by $30 \%$, the break-even moments of the five models only decreased by just over $1 \%$.

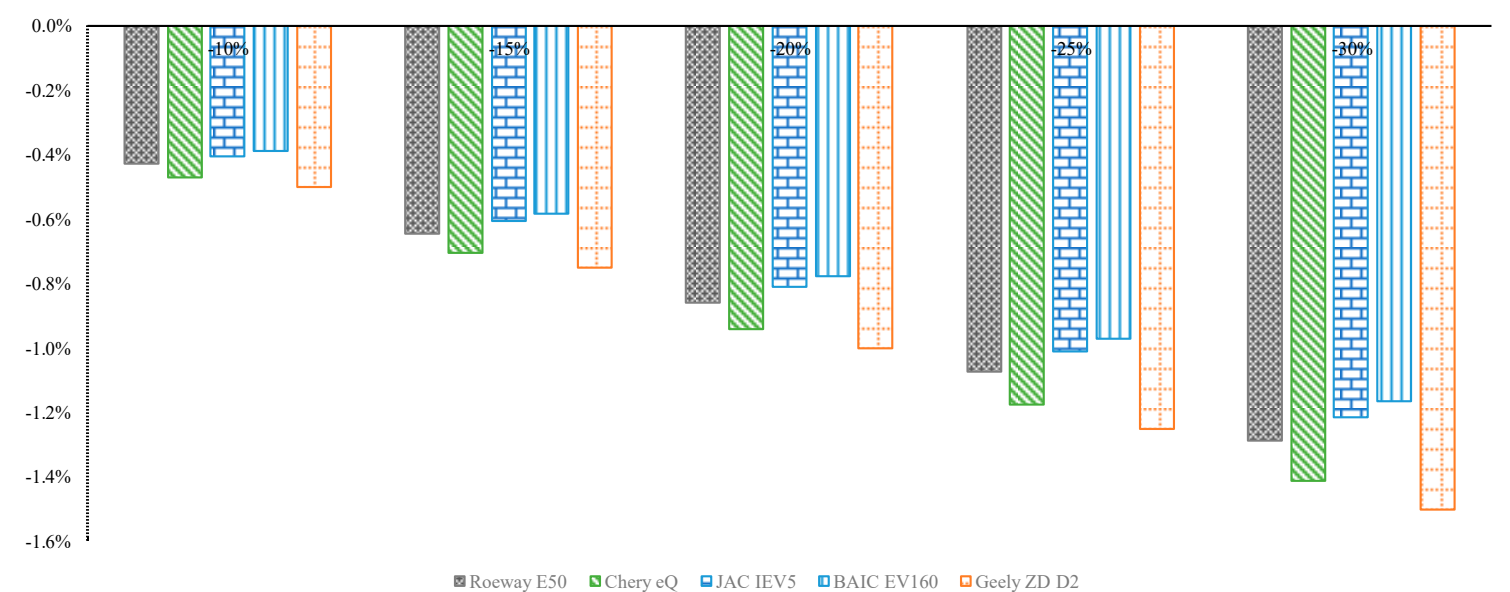

Figure 8. Sensitivity analysis of market price of a charging pile on break-even moment.

\subsubsection{Sensitivity Analysis of $\mathrm{P}_{\mathrm{e}}$}

The fifth variable is the electricity price. In China, the general commercial rate for electricity has been declining in recent years. The Chinese Premier's Government Work Report in 2018 called for a further $10 \%$ reduction in the average electricity price of general industry and commerce. NDRC issued Notice on the Reducing Electricity Prices of General Industry and Commerce in March 2018 and May 2019, in which different measures were taken to achieve the goal of $10 \%$ reduction. Thus, $P_{e}$ was also assumed to decrease the base value by $10 \%$ to $30 \%$ in this research. Figure 9 shows the sensitivity results, which showed that BAIC EV160 and Geely ZD D2 were more sensitive to the 
change of electricity price than the other EV models. In the scenario of a 30\% drop in electricity prices, the break-even moments of BAIC EV160 and Geely ZD D2 decreased by $5.22 \%$ and $4.79 \%$, respectively, compared to the base values. The response of Chery eQ was the smallest, which was only a decrease of $2.78 \%$ in the scenario of a $30 \%$ drop in electricity prices.

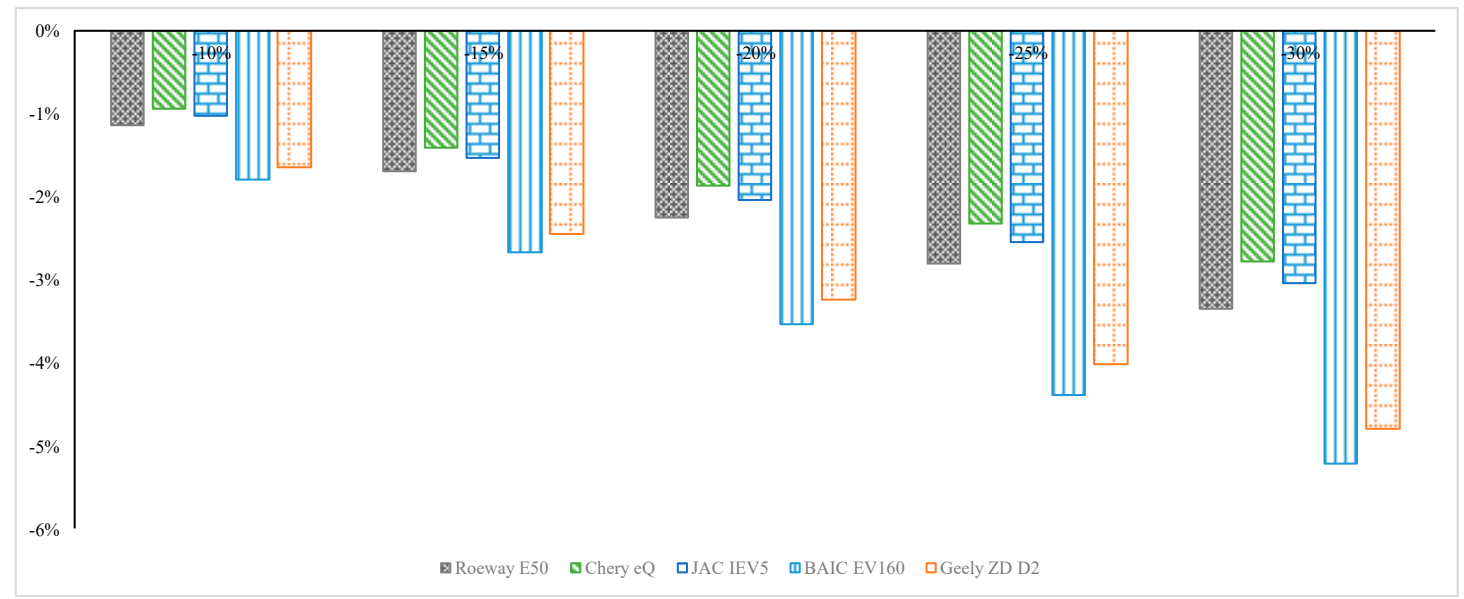

Figure 9. Sensitivity analysis of electricity price on break-even moment.

\subsubsection{Sensitivity Analysis of $\mathrm{C}_{\mathrm{OC}}$}

The sixth variable is the operational costs. Among them, the relocation cost was identified as a main component of the operational costs in previous studies $[13,67,79]$. In real-world operation, relocation cost is largely dependent on the labor cost [13]. Optimizing the relocation operation can reduce the demand for relocators and the workload of them, which greatly contributes to the decrease of operational costs. Meanwhile, as a function of total number of shared EVs and parking spots [80], relocation cost was estimated to increase with the expansion of ECS companies. The other cost components such as marketing cost and digital platform cost may also increase with the expansion of ECS companies. Therefore, $C_{O C}$ was assumed to range from $-30 \%$ to $20 \%$ in the sensitivity analysis (Table 12). The result presented in Figure 10 showed that the sensitivities of the five EV models to the change of operational costs were not significantly different. In the scenario of a $30 \%$ drop in operational costs, the largest decline of break-even moments was about 7.57\% (Geely ZD D2), and the smallest decline was about $5.88 \%$ (BAIC EV160).

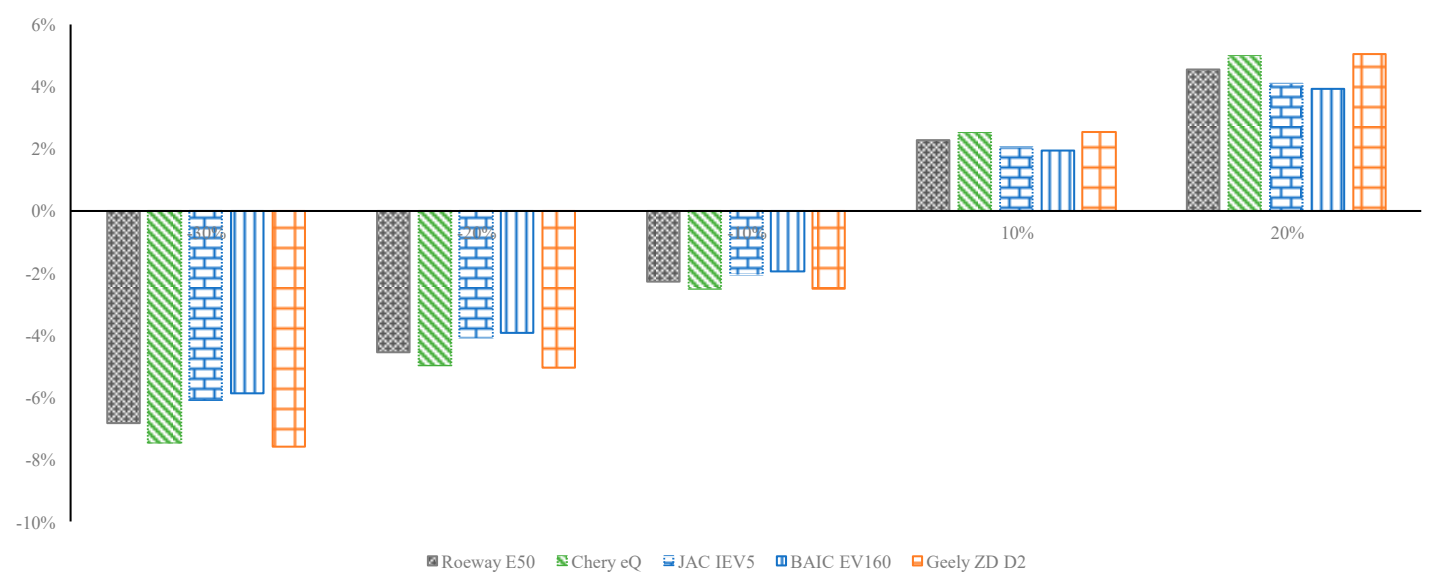

Figure 10. Sensitivity analysis of operational costs on break-even moment. 


\subsubsection{Sensitivity Analysis of $A$}

The last two variables analyzed are revenue-related variables. One is the unit rental price $(A)$, which was negatively correlated with the break-even moment. As elaborated above in Section 1 , the ECS industry in China has entered a deep adjustment period since 2017. The market began to differentiate, and some small-scale ECS companies with poor capability of profiting were forced to withdraw. Meanwhile, some large-scale ECS companies, having persistent development capability, may expand further. Thus, $A$ was also assumed to increase the base value by $10 \%$ to $30 \%$ in this research (Table 12). Figure 11 shows the sensitivity results, which showed that the sensitivity difference between the five EV models was small. The Roeway E50 was the most responsive model to the change of unit rental price compared to the other EV models, and the response of the Geely ZD D2 was the lowest. In the scenario of a $30 \%$ increase in unit rental price, the break-even moment of the Roeway E50 decreased by as much as $21.03 \%$, and that of the Geely ZD D2 decreased by $18.83 \%$ compared to the base values.

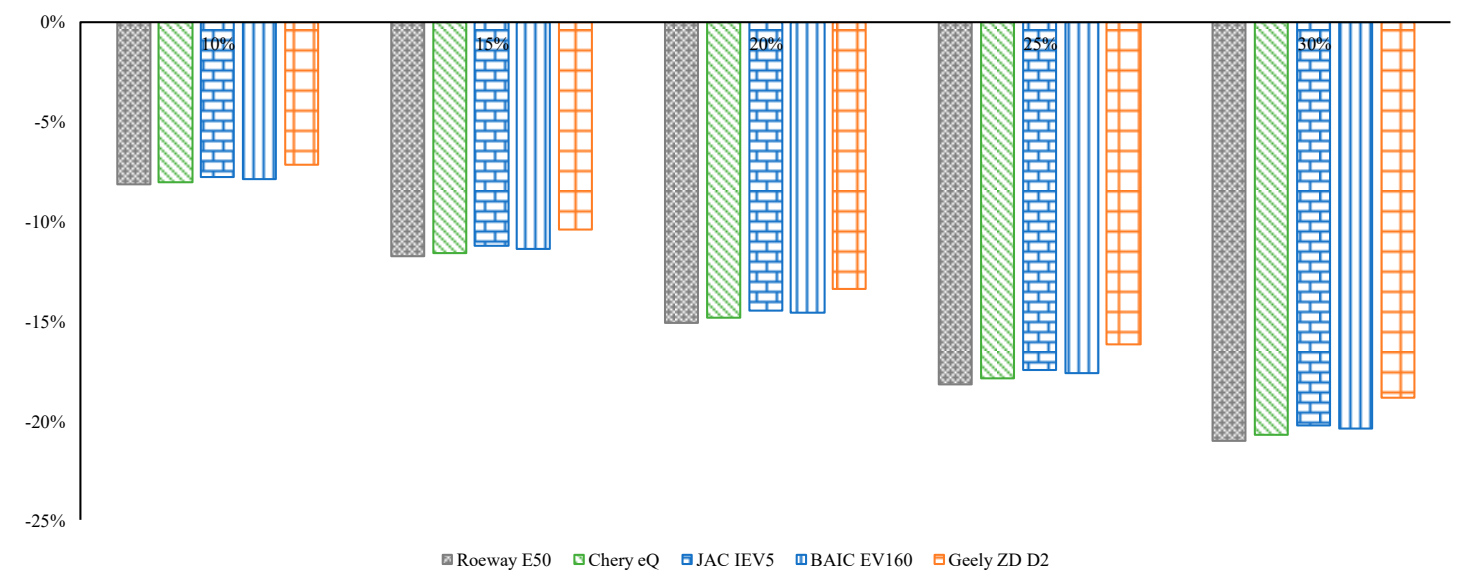

Figure 11. Sensitivity analysis of unit rental price on break-even moment.

\subsubsection{Sensitivity Analysis of $R_{A R}$}

The other revenue variable analyzed is non-rental revenue brought by per vehicle $\left(R_{A R}\right)$. Apart from rental revenue, non-rental revenue is also an important source of profit for ECS companies. Advertising revenue, which contributes the most to the current non-rental revenue, is predicated to increase with the increasing influence of ECS and the expansion of EVCARD and LCCS. Moreover, the non-rental revenue does not only involve advertising revenue. Big data-based service revenue, for example, is another critical source and is predicated to increase rapidly in the coming decades. Thus, $R_{A R}$ was also assumed to increase the base value by $30 \%$ to $100 \%$ in this research (Table 12). Figure 12 displays the sensitivity results, which showed that the break-even moments of the five EV models were not sensitive to the change in non-rental revenue. In the scenario with the lower bound, which assumed non-rental revenue per vehicle would increase by $30 \%$, none of the break-even moments of the five EV models was over $1 \%$. Similarly, in the scenario with the upper bound, which assumed non-rental revenue per vehicle would increase at twice the rate, the reaction range of the models' break-even moments was only between $2.45 \%$ and $3.04 \%$. 


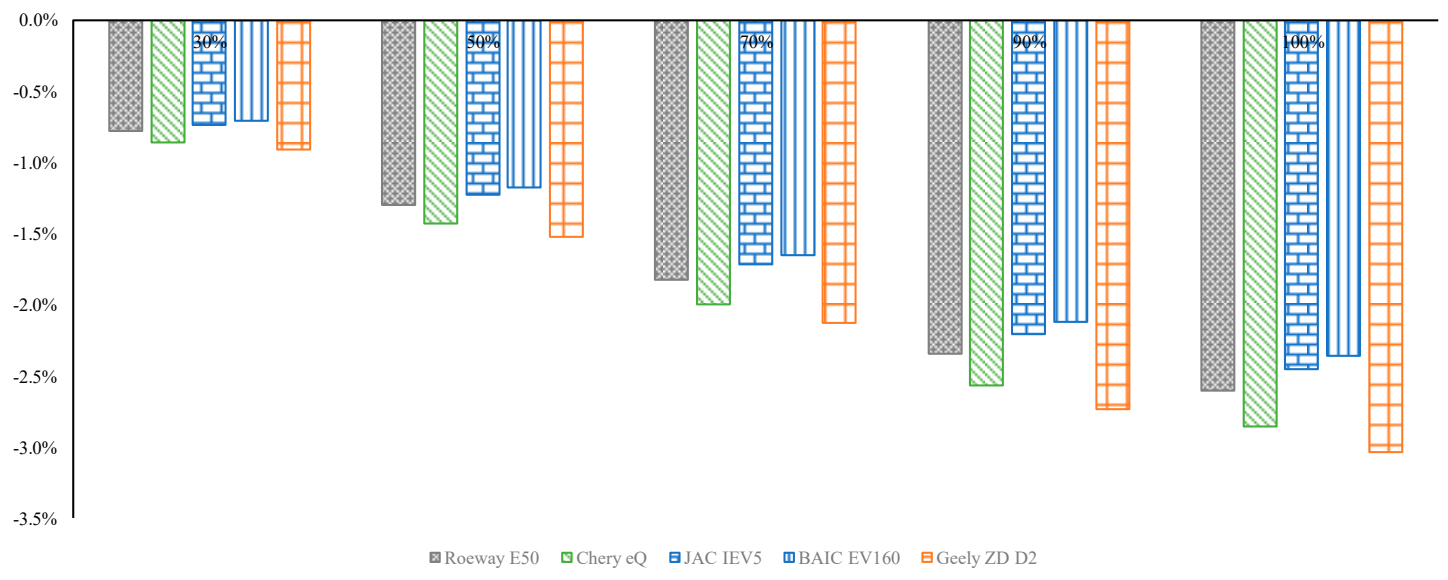

Figure 12. Sensitivity analysis of non-rental revenue on break-even moment.

\section{Discussion and Conclusions}

\subsection{Discussion}

Although uncertainty exists in the future values of the eight variables adopted in the sensitivity analysis, this paper is conducive to having a comprehensive and intuitive understanding of the operation of ECS companies.

Firstly, this study found that EVCARD can achieve an earlier break-even moment of the shared EVs than LCCS under the current cost and revenue conditions. The break-even moment of the Chery eQ of EVCARD is the shortest among the five EV models, at only $181.3 \mathrm{~min}$, followed by the Roeway E50 of EVCARD. The break-even moment of the BAIC EV160 of LCCS is the longest, namely $120.4 \mathrm{~min}$ longer than the Chery eQ. The Geely ZD D2 of LCCS is another model with a break-even moment over $300 \mathrm{~min}$.

Prior to the analysis, it was assumed that the purchase cost may be the major reason for the difference between the break-even moment of EVCARD and LCCS. However, the analysis in this paper suggests otherwise. The break-even moment of the Roeway E50, of which the purchase cost is the highest, is much smaller than that of the Geely ZD D2, of which the purchase cost is the lowest. The purchase costs of the Chery eQ (EVCARD) and BAIC EV160 (LCCS) are basically the same, yet the difference in their break-even moments is the biggest. The comparison of the life cycle cost and revenue between EVCARD and LCCS suggests that the main reason behind the break-even difference may be the unit rental price. EVCARD charges a rental price of CNY 0.6 CNY every minute, as well as a non-deductible insurance fee. By contrast, LCCS charges only CNY 0.3 or 0.4 per minute without an extra premium.

Secondly, the sensitivity analysis also reveals that wide difference exists in the influence of different variables on the break-even. Since the influence trend and magnitude of the five variables on each EV model is similar, this section takes the Roeway E50 as an illustrative example, as shown in Figure 13.

It is evident that the manufacturer suggested retail price $\left(\mathrm{C}_{\mathrm{MSRP}}\right)$, represented in blue dots, is the most influential variable to the break-even and is the only variable of which the decline rate is smaller than the response rate of the break-even in all five scenarios. When the manufacturer suggested retail price decreases by 30\%, EVCARD only needs to keep the Roeway E50 running for $110.2 \mathrm{~min}(1.8 \mathrm{~h}) \mathrm{a}$ day to achieve the break-even moment, $92.4 \mathrm{~min}$ shorter than the base break-even moment.

The reaction of break-even against the variation of unit rental price is the second largest. If EVCARD raises the unit rental price in CNY 0.78 per minute, the break-even moment of the Roeway E50 will be $42.6 \mathrm{~min}$ shorter than the base value. 


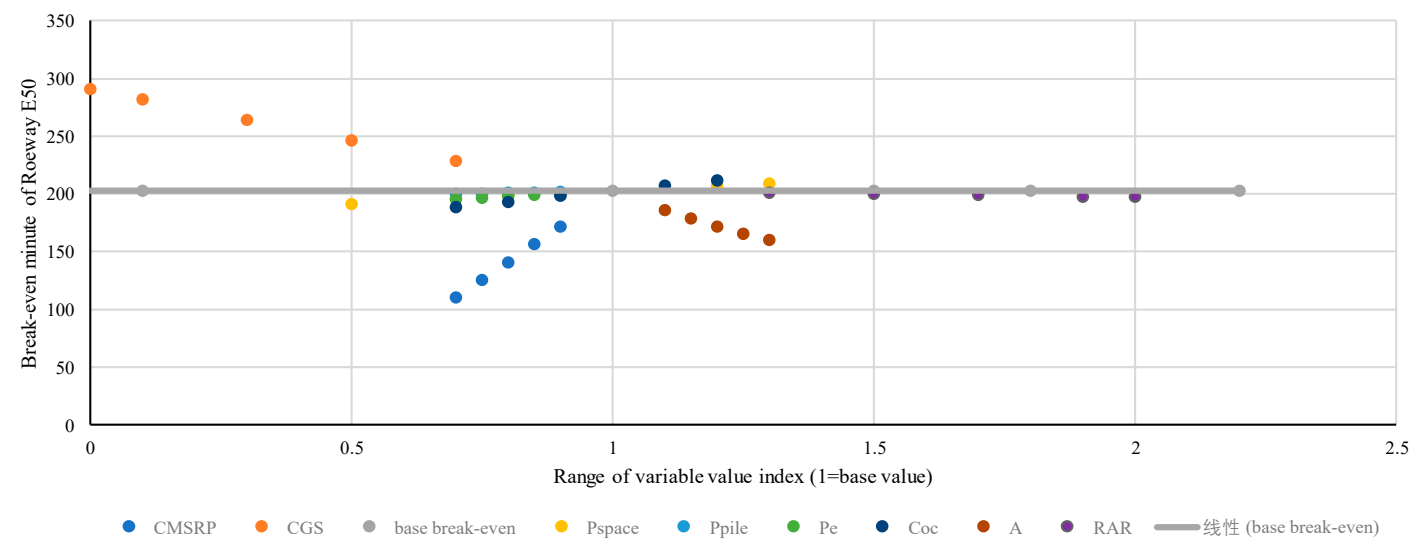

Figure 13. Break-even moments for the Roeway E50 in the sensitivity analysis of key variables.

The impact of government subsidy on break-even ranks third. The sensitivity analysis demonstrates that the break-even of the Roeway E50 will increase to $229 \mathrm{~min}(3.8 \mathrm{~h})$ if the government subsidy declines by $30 \%$ on the basis of 2017. In the worst case, where the subsidy is abolished, the break-even moment of the Roeway E50 will jump to $290.6 \mathrm{~min}$ (4.8 h), which would impose some burden on EVCARD's profitability. For ECS companies, it is very difficult for them to sustain profitability at the early development stage due to the large investment costs such as vehicle cost and infrastructure construction cost. The competitive between CS mode and other transportation modes makes it even more difficult. Therefore, many countries' governments implemented supportive policies for ECS to accelerate its take-off. For example, in South Korea, the government not only provide parking space for CS startups, but also adopted the public-private partnership (PPP) method to boost CS program development [81]. The Brazilian government launched its first ECS demonstration project (VAMO) in Fortaleza, which proved to have offered great benefits to urban mobility [82]. Some other cities also introduced CS demonstration and treated it as a sustainable business service, such as the Autolib programme in Paris, and the RFP (request for proposals) programme in San Francisco, which focused on reserving on-street parking spaces for CS vehicles. Munich allows free-floating carsharing operators to park everywhere and has lowered the price of the parking permit to $€ 900$ instead of $€ 1800$ for free-floating cars [83,84]. Many studies have argued that the success of the ECS service comes from close partnership between governments and ECS companies [85].

Operational cost per vehicle is the variable of which the influence on the break-even ranks fourth. However, unlike what is assumed, its influence is not very strong. The break-even moment of the Roeway E50 will only drop by 20 min with a 30\% decrease in operational cost. In turn, this may mean that operating costs must be substantially reduced on the current basis in order to achieve a significant decline in the break-even.

The effect of electricity price and rental of a parking spot is much the same. Reducing them by $30 \%$, the break-even will change from $202.6 \mathrm{~min}$ to 195.8 and $196 \mathrm{~min}$, respectively. The other two variables that have a negligible effect in the sensitivity analysis is market price of a charging pile and other revenues per vehicle, especially the latter. Varying other revenue from $30 \%$ to $100 \%$ will only decrease the break-even of the Roeway E50 from by $0.78 \%$ to $2.6 \%$. This may mean that ECS companies can hardly rely on current other revenue to make a profit.

\subsection{Conclusions}

ECS is generally accepted as an innovative mobility mode to alleviate the persistent unsustainable problems in the transportation sector. In real-world operation, the question of how to realize profit for ECS companies is a critical issue that the sustainable development of ECS must address. Previous literature on this issue, however, is scarce, and most only examines the benefits of ECS to society and users. Through an empirical quantitative analysis, this research fulfills a current gap in the 
existing academic CS/ECS literature by examining the break-even conditions for ECS companies. The life-cycle cost and the monetary economic revenues of ECS companies are considered in the break-even analysis. More importantly, a sensitivity analysis was further conducted to analyze how different factors influence the profitability of ECS companies.

This research takes two influential Chinese ECS companies, namely EVCARD and LCCS, as case studies. These two companies are both located in large Chinese cities, as are most of the CS companies. According to the study of Kortum et al., the demographic and economic descriptors of different cities may play determining roles in the development of the CS services [85]. They found the city's residential density has a positive effect on CS development, which can explain why most CS companies currently selected big cities as main market. It is an important method to solve the "last kilometer" problem in the big cities. However, in the long term, the development of CS/ECS will not be limited to big cities, considering the fierce market competition and its role in accelerating sustainable transportation. After exploring the development experiences, it should be gradually expanded to small and medium-sized cities. For example, EVCARD is now distributing its operation in small and medium-sized cities, such as Huangshan and Guiyang.

In this paper, the break-even moments of five main EV models belonging to the two companies are determined. Findings from our case study show that ECS companies with the B2C model are facing great challenge in making profits under the current cost and benefit conditions. For EVCARD, each!shared EVs must run for at least three to four hours before the company can make a profit. Taking its huge fleet size into account, however, that may be very difficult for EVCARD. For LCCS, each shared EVs must run for about five hours before the company can make a profit. As a result, it may be more difficult for LCCS to make profits. However, the relatively small fleet size and more importantly, the characteristic of multi-operators of LCCS, can mitigate the impact of possible losses on each operator to a certain extent.

Although the increase of rental price can shorten the break-even moment, too high a rental price may reduce the attractiveness of ECS for consumers, considering the fierce competition in the CS/ECS market and the substitution of other mobility modes. Exploring appropriate pricing strategies is thus one way for CS operators to get more market share in the competitive market [86]. For example, dynamic pricing is regarded as a useful strategy in the most recent studies to improve operator profits [87]. Jorge et al. [88] argued that operators should decrease the rental price when a car-sharing trip can benefit the balance of the system, and thus increase the profit. Ciari et al. [86] further pointed out that different pricing strategies can not only increase or decrease the demand but also impact the usage patterns, i.e., who will use the carsharing and when and where. In addition to the pricing strategies, providing users with better value proposition is also important for ECS companies [89]. Perboli et al. [89] demonstrated that consumers' choices about carsharing are influenced by many factors other than rental price, such as perceived quality of the service and vehicle model varieties. Therefore, CS companies should adopt a variety of methods to cooperate with the pricing mechanism to attract consumers.

Meanwhile, ECS companies should explore various ways to cut down the life-cycle cost, especially the car purchase cost, operational cost, and rental cost of parking spaces, such as through the exploration of multi-operators by LCCS. For ECS companies, it is important and imperative to establish cooperation with more commercial organizations to help reduce the rental cost of parking spaces, especially considering the scarcity of land resources in some Chinese megacities such as Beijing, Shanghai, and Shenzhen. Overly-high operational cost, especially relocation cost, is the key reason why many ECS companies are losing money. The sensitivity analysis shows that operational cost must be substantially reduced on the current basis in order to increase profitability. ECS companies may need to design appropriate operational policies to reduce the relocation cost, such as dynamic pricing, i.e., the rental fees vary with the vehicle availability [90]. Tapping other sources of revenue can help alleviate ECS companies' huge cost burden. However, the sensitivity analysis reports that existing other revenues are extremely limited and have little impact on increasing the possibility of profitability. 
The results of this paper provide some useful insights for policy-makers. Currently, in the ECS industry, the operators are suffering great pressure due to vast investment and limited demand. As shown in the above analysis, the manufacturer suggested retail price of EVs is the most influential factor for the operators. Therefore, the government should pay more attention to the roles of policies for EV cost reduction in the coming "Fourteenth Five Year Planning", such as the policies for R\&D, which can not only promote the diffusion of EVs, but also increase the profitability of ECS companies. Moreover, findings also show that the supportive policies from the government, such as financial subsidy and decreasing electricity prices, play important roles in operators' profitability. Therefore, the government should try to avoid the negative effects of immediate abolition of subsidies and provide ECS companies with niche protection through gradual decline of the subsidy scheme. In addition, the government should emphasize policy mixes rather than single policies. Low interest loans, tax relief, and demonstration, which increases the awareness of consumers about ECS, should also be introduced.

However, there are several limitations to our research. This paper assumes annual operational costs to be fixed values, and the study is limited by data availability. In fact, operational cost would vary with the change of many variables, such as fleet size, network of stations, operational time of vehicles, travel routes of users, and battery recharging constraint. Moreover, the composition of life-cycle cost of Chinese ECS companies may not be applicable to other countries or areas. Nevertheless, our results are still inspiring for the companies in other countries or areas.

Author Contributions: Writing-original draft preparation, J.J.; validation, S.M.; methodology, Y.X.; writing-review and editing, D.K. All authors have read and agreed to the published version of the manuscript.

Funding: This research was funded by the National Natural Science Foundation of China (Grant No. 71802127) and the key projects in soft science research of Shanghai Science and Technology Commission (Grant No. 19692102800; Grant No. 20692108900).

Conflicts of Interest: The authors declare no conflict of interest. 


\section{Abbreviations}

\begin{tabular}{|c|c|c|c|}
\hline $\mathrm{AC}$ & alternating current & $\mathrm{C}_{\mathrm{OC}}$ & operational cost per vehicle per year \\
\hline B2C & business-to-consumer & $\mathrm{C}_{\mathrm{PSC}}$ & parking spot cost of a shared EV per year \\
\hline CS & carsharing & $\mathrm{DM}$ & average daily mileage \\
\hline $\mathrm{DC}$ & direct current & ECR & energy consumption ratio of an EV \\
\hline ECS & electric carsharing & $\mathrm{I}_{\mathrm{BP}}$ & basic premium \\
\hline EV & electric vehicle & $\mathrm{I}_{\mathrm{CI}}$ & compulsory traffic insurance \\
\hline $\mathrm{kW}$ & kilowatt & $\mathrm{I}_{\mathrm{DI}}$ & "non-deductible" insurance \\
\hline $\mathrm{kWh}$ & kilowatt hour & $\mathrm{I}_{\mathrm{LI}}$ & loss liability insurance \\
\hline MIIT & $\begin{array}{l}\text { Ministry of Industry and Information } \\
\text { Technology }\end{array}$ & $\mathrm{I}_{\mathrm{PI}}$ & vehicle personnel liability insurance \\
\hline MOST & Ministry of Science and Technology & $\mathrm{I}_{\mathrm{TI}}$ & commercial third-party insurance \\
\hline MOF & Ministry of Finance & $\mathrm{N}$ & service lifespan of a shared EV \\
\hline NDRC & $\begin{array}{l}\text { National Development and Reform } \\
\text { Commission }\end{array}$ & $\mathrm{N}_{\mathrm{c}}$ & depreciation period of a charging pile \\
\hline NPV & net present value & $\mathrm{P}_{\mathrm{e}}$ & price of electricity \\
\hline $\mathrm{P} 2 \mathrm{P}$ & peer-to-peer & $P_{\text {pile }}$ & market price of a charging pile \\
\hline PV & present value & $\mathrm{P}_{\mathrm{m}}$ & life-cycle maintenance cost of an EV per $\mathrm{km}$ \\
\hline SAT & State Administration of Taxation & $P_{\text {space }}$ & rental of a parking spot of a shared EV per year \\
\hline SHDRC & $\begin{array}{l}\text { Shanghai Development and Reform } \\
\text { Commission }\end{array}$ & $\mathrm{PV}_{\mathrm{C}}$ & $\begin{array}{l}\text { present value of the life-cycle costs of a shared } \\
\text { EV }\end{array}$ \\
\hline SHEIC & $\begin{array}{l}\text { Shanghai Economic Informatization } \\
\text { Committee }\end{array}$ & $P V_{R}$ & present value of the revenue of a shared EV \\
\hline SHFB & Shanghai Finance Bureau & $\mathrm{R}_{\mathrm{AR}}$ & average advertising revenue per EV per year \\
\hline SZDRC & $\begin{array}{l}\text { Shenzhen Development and Reform } \\
\text { Commission }\end{array}$ & $\mathrm{R}_{\mathrm{RR}}$ & rental revenue of a shared EV per year \\
\hline SZMPG & $\begin{array}{l}\text { Shenzhen Municipal People's } \\
\text { Government }\end{array}$ & $\mathrm{R}_{\mathrm{RV}}$ & residual value of a shared $\mathrm{EV}$ \\
\hline $\mathrm{TCO}$ & total costs of ownership & $\mathrm{r}$ & discount rate \\
\hline Symbols & & $\mathrm{r}_{\mathrm{c}}$ & residual value rate of a charging pile \\
\hline A & unit price of renting a shared EV & Speed & average driving speed of a shared EVv \\
\hline B & other costs for users to rent a shared EV & & $\begin{array}{l}\text { total minutes a shared EV is rented for in } \\
\text { one day }\end{array}$ \\
\hline $\mathrm{C}_{\mathrm{CPC}}$ & $\begin{array}{l}\text { charging pile costs shared by an EV per } \\
\text { year }\end{array}$ & $\mathrm{r}_{\alpha}$ & number ratio of parking spots to EVs \\
\hline $\mathrm{C}_{\mathrm{EC}}$ & energy costs of an EV per year & $\beta$ & the number ratio of charging piles to EVs \\
\hline $\mathrm{C}_{\mathrm{GS}}$ & government subsidy granted to an EV & $\eta$ & charging efficiency \\
\hline $\mathrm{C}_{\mathrm{IC}}$ & insurance cost of an EV per year & $\lambda$ & annual depreciation rate of a shared EV \\
\hline $\mathrm{C}_{\mathrm{MC}}$ & maintenance cost of an EV per year & $\theta$ & cost ratio of battery to the whole vehicle \\
\hline $\mathrm{C}_{\mathrm{MSRP}}$ & $\begin{array}{l}\text { manufacturer suggested retail price of } \\
\text { an EV }\end{array}$ & $\delta_{1}$ & depreciation value of an ICEV per $\mathrm{km}$ \\
\hline $\mathrm{C}_{\mathrm{PC}}$ & purchase cost of an EV & $\delta_{2}$ & depreciation value of a battery per $\mathrm{km}$ \\
\hline
\end{tabular}

\section{References}

1. Muñoz, P.; Cohen, B. Mapping out the sharing economy: A configurational approach to sharing business modeling. Technol. Forecast. Soc. Chang. 2017, 125, 21-37. [CrossRef]

2. Acquier, A.; Daudigeos, T.; Pinkse, J. Promises and paradoxes of the sharing economy: An organizing framework. Technol. Forecast. Soc. Chang. 2017, 125, 1-10. [CrossRef]

3. Ritter, M.; Schanz, H. The sharing economy: A comprehensive business model framework. J. Clean. Prod. 2019, 213, 320-331. [CrossRef]

4. Guyader, H.; Piscicelli, L. Business model diversification in the sharing economy: The case of GoMore. J. Clean. Prod. 2019, 215, 1059-1069. [CrossRef] 
5. Ma, Y.; Rong, K.; Mangalagiu, D.; Thornton, T.F.; Zhu, D. Co-evolution between urban sustainability and business ecosystem innovation: Evidence from the sharing mobility sector in Shanghai. J. Clean. Prod. 2018, 188, 942-953. [CrossRef]

6. Geissinger, A.; Laurell, C.; Öberg, C.; Sandström, C. How sustainable is the sharing economy? On the sustainability connotations of sharing economy platforms. J. Clean. Prod. 2019, 206, 419-429. [CrossRef]

7. Moradi, A.; Vagnoni, E. A multi-level perspective analysis of urban mobility system dynamics: What are the future transition pathways? Technol. Forecast. Soc. Chang. 2018, 126, 231-243. [CrossRef]

8. Meng, Z.; Li, E.Y.; Qiu, R. Environmental sustainability with free-floating carsharing services: An on-demand refueling recommendation system for Car2go in Seattle. Technol. Forecast. Soc. Chang. 2020, 152, 119893. [CrossRef]

9. Firnkorn, J.; Müller, M. What will be the environmental effects of new free-floating car-sharing systems? The case of Car2go in Ulm. Ecol. Econ. 2011, 70, 1519-1528. [CrossRef]

10. Cohen, B.; Kietzmann, J. Ride on! Mobility business models for the sharing economy. Organ. Environ. 2014, 27, 279-296. [CrossRef]

11. Aversa, P.; Haefliger, S.; Reza, D.G. Building a winning business model portfolio. MIT Sloan Manag. Rev. 2017, 58, 49-54. Available online: https://sloanreview.mit.edu/article/building-a-winning-business-modelportfolio/ (accessed on 20 June 2020).

12. Granovskii, M.; Dincer, I.; Rosen, M.A. Economic and environmental comparison of conventional, hybrid, electric and hydrogen fuel cell vehicles. J. Power Sources 2006, 159, 1186-1193. [CrossRef]

13. Gambella, C.; Malaguti, E.; Masini, F.; Vigo, D. Optimizing relocation operations in electric car-sharing. Omega 2018, 81, 234-245. [CrossRef]

14. Hu, S.; Chen, P.; Lin, H.; Xie, C.; Chen, X. Promoting carsharing attractiveness and efficiency: An exploratory analysis. Transp. Res. Part D 2018, 65, 229-243. [CrossRef]

15. Lagadic, M.; Verloes, A.; Louvet, N. Can carsharing services be profitable? A critical review of established and developing business models. Transp. Policy 2019, 77, 68-78. [CrossRef]

16. Teece, D.J. Business models, business strategy and innovation. Long Range Plan. 2010, 43, 172-194. [CrossRef]

17. Yang, M.; Evans, S.; Vladimirova, D.; Rana, P. Value uncaptured perspective for sustainable business model innovation. J. Clean. Prod. 2017, 140, 1794-1804. [CrossRef]

18. Axsen, J.; Sovacool, B.K. The roles of users in electric, shared and automated mobility transitions. Transp. Res. Part D 2019, 71, 1-21. [CrossRef]

19. Mattia, G.; Mugion, R.G.; Principato, L. Shared mobility as a driver for sustainable consumptions: The intention to re-use free-floating car sharing. J. Clean. Prod. 2019, 237, 117404. [CrossRef]

20. Sprei, F.; Habibi, S.; Englund, C.; Pettersson, S.; Voronov, A.; Wedlin, J. Free-floating car-sharing electrification and mode displacement: Travel time and usage patterns from 12 cities in Europe and the United States. Transp. Res. Part D 2019, 71, 127-140. [CrossRef]

21. Lemme, R.F.; Arruda, E.F.; Bahiense, L. Optimization model to assess electric vehicles as an alternative for fleet composition in station-based car sharing systems. Transp. Res. Part D 2019, 67, 173-196. [CrossRef]

22. Brandstätter, G.; Kahr, M.; Leitner, M. Determining optimal locations for charging stations of electric car-sharing systems under stochastic demand. Transp. Res. Part B 2017, 104, 17-35. [CrossRef]

23. Mounce, R.; Nelson, J.D. On the potential for one-way electric vehicle car-sharing in future mobility systems. Transp. Res. Part A 2019, 120, 17-30. [CrossRef]

24. Nijland, H.; Van Meerkerk, J. Mobility and environmental impacts of car sharing in the Netherlands. Environ. Innov. Soc. Transit. 2017, 23, 84-91. [CrossRef]

25. Wang, X.; Lu, M.; Mao, W.; Ouyang, J.; Zhou, B.; Yang, Y. Improving benefit-cost analysis to overcome financing difficulties in promoting energy-efficient renovation of existing residential buildings in China. Appl. Energy 2015, 141, 119-130. [CrossRef]

26. Noel, L.; McCormack, R. A cost benefit analysis of a V2G-capable electric school bus compared to a traditional diesel school bus. Appl. Energy 2014, 126, 246-255. [CrossRef]

27. Palencia, J.C.G.; Furubayashi, T.; Nakata, T. Techno-economic assessment of lightweight and zero emission vehicles deployment in the passenger car fleet of developing countries. Appl. Energy 2014, 123, 129-142. [CrossRef]

28. Hao, H.; Cheng, X.; Liu, Z.; Zhao, F. Electric vehicles for greenhouse gas reduction in China: A cost-effectiveness analysis. Transp. Res. Part D 2017, 56, 68-84. [CrossRef] 
29. Gopal, A.R.; Park, W.Y.; Witt, M.; Phadke, A. Hybrid- and battery-electric vehicles offer low-cost climate benefits in China. Transp. Res. Part D 2018, 62, 362-371. [CrossRef]

30. Qiao, Q.; Zhao, F.; Liu, Z.; He, X.; Hao, H. Life cycle greenhouse gas emissions of Electric Vehicles in China: Combining the vehicle cycle and fuel cycle. Energy 2019, 177, 222-233. [CrossRef]

31. Onat, N.C.; Kucukvar, M.; Afshar, S. Eco-efficiency of electric vehicles in the United States: A life cycle assessment based principal component analysis. J. Clean. Prod. 2019, 212, 515-526. [CrossRef]

32. Thiel, C.; Perujo, A.; Mercier, A. Cost and CO2 aspects of future vehicle options in Europe under new energy policy scenarios. Energy Policy 2010, 38, 7142-7151. [CrossRef]

33. Weiss, M.; Patel, M.K.; Junginger, M.; Perujo, A.; Bonnel, P.; Van Grootveld, G. On the electrification of road transport-Learning rates and price forecasts for hybrid-electric and battery-electric vehicles. Energy Policy 2012, 48, 374-393. [CrossRef]

34. Wu, G.; Inderbitzin, A.; Bening, C. Total cost of ownership of electric vehicles compared to conventional vehicles: A probabilistic analysis and projection across market segments. Energy Policy 2015, 80, 196-214. [CrossRef]

35. Van Velzen, A.; Annema, J.A.; Van De Kaa, G.; Van Wee, B. Proposing a more comprehensive future total cost of ownership estimation framework for electric vehicles. Energy Policy 2019, 129, 1034-1046. [CrossRef]

36. Moon, S.; Lee, D.-J. An optimal electric vehicle investment model for consumers using total cost of ownership: A real option approach. Appl. Energy 2019, 253, 113494. [CrossRef]

37. Tanco, M.; Cat, L.; Garat, S. A break-even analysis for battery electric trucks in Latin America. J. Clean. Prod. 2019, 228, 1354-1367. [CrossRef]

38. Fellows, N.; Pitfield, D. An economic and operational evaluation of urban car-sharing. Transp. Res. Part D 2000, 5, 1-10. [CrossRef]

39. Rabbitt, N.; Ghosh, B. Economic and environmental impacts of organised Car Sharing Services: A case study of Ireland. Res. Transp. Econ. 2016, 57,3-12. [CrossRef]

40. Schlüter, J.; Weyer, J. Car sharing as a means to raise acceptance of electric vehicles: An empirical study on regime change in automobility. Transp. Res. Part F 2019, 60, 185-201. [CrossRef]

41. State Information Center. China Sharing Economy Development Report 2018. Available online: http: //www.sic.gov.cn/News/557/9904.htm (accessed on 20 June 2020).

42. State Council. Government Work Report 2019. Available online: http://www.gov.cn/premier/2019-03/16/ content_5374314.htm (accessed on 20 June 2020).

43. State Council. Government Work Report 2018. Available online: http://www.gov.cn/premier/2018-03/22/ content_5276608.htm (accessed on 20 June 2020).

44. State Council. Government Work Report 2017. Available online: http://www.gov.cn/premier/2017-03/16/ content_5177940.htm (accessed on 20 June 2020).

45. State Information Center (SIC). China Sharing Economy Development Report 2019. Available online: http://www.sic.gov.cn/News/557/9904.htm (accessed on 20 June 2020).

46. General Office of the State Council. Guidance on Accelerating the Promotion and Application of New Energy Vehicles. Available online: http://www.gov.cn/zhengce/content/2014-07/21/content_8936.htm (accessed on 20 June 2020).

47. iResearch Consulting Group. China Sharing Industry and User Research Report 2017. Available online: http://www.sohu.com/a/219176882_115250 (accessed on 20 June 2020).

48. Roland Berger. How Can Carsharing Succeed in China? Available online: http://www.sohu.com/a/136502838_ 495912 (accessed on 20 June 2020).

49. Huang, C.H. New Opportunities for Platform Operation of Carsharing Based on "User-Centered". Available online: http://auto.people.com.cn/n1/2019/0624/c1005-31176031.html (accessed on 20 June 2020).

50. Cao, G.Y. Several Changes in the Future Carsharing Industry. Available online: https://www.evcard.com/ find/detail/id/183.html (accessed on 20 June 2020).

51. MOF; MOST (Ministry of Science and Technology); MIIT (Ministry of Industry and Information Technology); NDRC (National Development and Reform Commission). Notice on Further Promotion and Application of New Energy Vehicles. Available online: http://www.most.gov.cn/tztg/201402/t20140212_111801.htm (accessed on 20 June 2020).

52. SHDRC (Shanghai Development and Reform Commission); SHEIC (Shanghai Economic Informatization Committee); SHFB (Shanghai Finance Bureau); SSTC (Shanghai Science and Technology Commission); STC 
(Shanghai Transportation Commission); SMFB (Shanghai Municipal Finance Bureau); SPS (Shanghai Police Station). Interim Measures for Shanghai to Encourage the Purchase and Use of New Energy Vehicles. Available online: http://www.shanghai.gov.cn/nw2/nw2314/nw2319/nw10800/nw11408/nw31831/u26aw39123.html (accessed on 20 June 2020).

53. SZMPG (Shenzhen Municipal People's Government). Notice of Several Policy Measures for the Promotion and Application of New Energy Vehicles in Shenzhen. Available online: http://www.sz.gov.cn/zfgb/2015/ gb911/201503/t20150304_2822781.htm (accessed on 20 June 2020).

54. MOF; MOST; MIIT; NDRC. Notice on the Financial Support Policy for the Promotion and Application of New Energy Vehicles in 2016-2020. Available online: http://jjs.mof.gov.cn/zhengwuxinxi/zhengcefagui/201504/ t20150429_1224515.html (accessed on 20 June 2020).

55. SHDRC; SHEIC; SHFB; SSTC; STC; SMFB; SPS. Interim Measures for Shanghai to Encourage the Purchase and Use of New Energy Vehicles. Available online: http://www.shanghai.gov.cn/nw2/nw2314/nw2319/ nw12344/u26aw47043.html (accessed on 20 June 2020).

56. SZDRC (Shenzhen Development and Reform Commission). Notice of the Financial Support Policy for the Promotion and Application of New Energy Vehicles in Shenzhen in 2016. Available online: http://www.sz.gov.cn/fzggj/qt/tzgg/201609/t20160905_4413330.htm (accessed on 20 June 2020).

57. SHDRC; SHEIC; SHFB; SSTC; STC; SMFB; SPS. Interim Measures for Shanghai to Encourage the Purchase and Use of New Energy Vehicles. Available online: http://www.shanghai.gov.cn/nw2/nw2314/nw2319/ nw10800/nw11408/nw41435/u26aw52791.html (accessed on 20 June 2020).

58. SZDRC. Notice of the Financial Support Policy for the Promotion and Application of New Energy Vehicles in Shenzhen in 2017. Available online: http://www.sz.gov.cn/zfgb/2017/gb1016/201708/t20170816_8142020.htm (accessed on 20 June 2020).

59. MOF; MOST; MIIT; NDRC. Notice on Adjusting and Perfecting the Policy of Financial Subsidies for the Promotion and Application of New Energy Vehicles. Available online: http://jjs.mof.gov.cn/zhengwuxinxi/ zhengcefagui/201802/t20180213_2815574.html (accessed on 20 June 2020).

60. SHDRC; SHEIC; SHFB; SSTC; STC; SMFB; SPS. Measures to Encourage the Purchase and Use of New Energy Vehicles in Shanghai. Available online: http://www.shanghai.gov.cn/nw2/nw2314/nw2319/nw12344/ u26aw55046.html (accessed on 20 June 2020).

61. SZDRC. Notice of the Financial Support Policy for the Promotion and Application of New Energy Vehicles in Shenzhen in 2018. Available online: http://www.sz.gov.cn/zfgb/2019/gb1087/201901/t20190130_15533201.htm (accessed on 20 June 2020).

62. MIIT; SAT. Catalogue of New Energy Vehicle Models Exempted from Vehicle Purchase Tax (Sixth batch). Available online: http://www.chinatax.gov.cn/n810341/n810755/c3805959/content.html (accessed on 20 June 2020).

63. MIIT; SAT. Catalogue of New Energy Vehicle Models Exempted from Vehicle Purchase Tax (First batch). Available online: http://www.chinatax.gov.cn/n810341/n810755/c3805763/content.html (accessed on 20 June 2020).

64. MIIT; SAT. Catalogue of New Energy Vehicle Models Exempted from Vehicle Purchase Tax (Seventh batch). Available online: http://www.chinatax.gov.cn/n810341/n810765/n1990035/n1990077/c2193644/content.html? from $=$ singlemessage (accessed on 20 June 2020).

65. MIIT; SAT. Catalogue of New Energy Vehicle Models Exempted from Vehicle Purchase Tax (Eighth batch). Available online: http://www.miit.gov.cn/n1146285/n1146352/n3054355/n3057585/n3057590/c5400779/content. html (accessed on 20 June 2020).

66. MIIT; SAT. Catalogue of New Energy Vehicle Models Exempted from Vehicle Purchase Tax (Fourth batch). Available online: http://www.chinatax.gov.cn/n810341/n810755/c3805855/content.html (accessed on 20 June 2020).

67. Weikl, S.; Bogenberger, K. A practice-ready relocation model for free-floating carsharing systems with electric vehicles-Mesoscopic approach and field trial results. Transp. Res. C 2015, 57, 206-223. [CrossRef]

68. NDRC. Notice on Issues Relating to Electricity Price of Electric Vehicle. Available online: http://jgs.ndrc.gov. cn/zcfg/201408/t20140801_621052.html (accessed on 20 June 2020).

69. Zhu, N.; Ouyang, M.; Lu, L.; Jing, F.A. Benefit sensitivity analysis of medium/low speed electric vehicle. Automot. Eng. 2012, 34, 859-863. (In Chinese) 
70. Didi Company. Urban Transportation Travel Report 2018. Available online: http://dy.163.com/v2/article/ detail/EC1HLMKB0511B3FV.html (accessed on 20 June 2020).

71. Wang, N.; Gong, Z.Y.; Zhao, J. Consumer Ownership Cost Model of Plug-in Hybrid Electric Vehicle. J. Tongji Univ. 2012, 5, 793-799. (In Chinese)

72. Ruan, P.; Cao, X. Medium-term renewal strategy of vehicles in logistics enterprises. J. Wuhan Univ. Technol. 2015, 3, 542-546. (In Chinese)

73. Bingxiang, S.; Tingting, H.; Junlong, N. Operational cost evaluation and prognosis of pure electric bus based on battery swap and leasing mode. Trans. China Electrotech. Soc. 2014, 4, 316-322. (In Chinese)

74. Wang, D.; Coignard, J.; Zeng, T.; Zhang, C.; Saxena, S. Quantifying electric vehicle battery degradation from driving vs. vehicle-to-grid services. J. Power Sources 2016, 332, 193-203. [CrossRef]

75. Xu, B.; Oudalov, A.; Ulbig, A.; Andersson, G.; Kirschen, D.S. Modeling of lithium-ion battery degradation for cell life assessment. IEEE Trans. Smart Grid 2016, 9, 1131-1140. [CrossRef]

76. Xue, Y.X.; Chen, Y.; Kong, D.Y. Business model innovation of electric vehicle based on value network. Sci. Sci. Manag. S. T. 2014, 3, 49-57. (In Chinese)

77. Dai, J.Q. Power Battery Cost will Be Reduced to 775 CNY/kWh. Available online: https://tech.sina.com.cn/ roll/2017-11-15/doc-ifynvxeh4749481.shtml (accessed on 20 June 2020).

78. Wang, N.; Tang, L.; Zhang, W.; Guo, J. How to face the challenges caused by the abolishment of subsidies for electric vehicles in China? Energy 2019, 166, 359-372. [CrossRef]

79. Yoon, T.; Cherry, C.; Ryerson, M.S.; Bell, J.E. Carsharing demand estimation and fleet simulation with EV adoption. J. Clean. Prod. 2019, 206, 1051-1058. [CrossRef]

80. Deng, Y.; Cardin, M.-A. Integrating operational decisions into the planning of one-way vehicle-sharing systems under uncertainty. Transp. Res. Part C 2018, 86, 407-424. [CrossRef]

81. Kang, J.; Hwang, K.; Park, S. Finding factors that influence carsharing usage: Case study in seoul. Sustainability 2016, 8, 709. [CrossRef]

82. Luna, T.F.; Uriona-Maldonado, M.; Silva, M.E.; Vaz, C.R. The influence of e-carsharing schemes on electric vehicle adoption and carbon emissions: An emerging economy study. Transp. Res. Part D 2020, 79, 102226. [CrossRef]

83. Terrien, C.; Maniak, R.; Chen, B.; Shaheen, S.A. Good practices for advancing urban mobility innovation: A case study of one-way carsharing. Res. Transp. Bus. Manag. 2016, 20, 20-32. [CrossRef]

84. Kyei, R.O.; Chan, A. Review of studies on the critical success factors for Public-Private Partnership (PPP) projects from 1990 to 2013. Int. J. Proj. Manag. 2015, 33, 1335-1346. [CrossRef]

85. Kortum, K.; Schönduwe, R.; Stolte, B.; Bock, B. Free-floating carsharing: City-specific growth rates and success factors. Transp. Res. Procedia 2016, 19, 328-340. [CrossRef]

86. Ciari, F.; Balac, M.; Balmer, M. Modelling the effect of different pricing schemes on free-floating carsharing travel demand: A test case for Zurich, Switzerland. Transportation 2015, 42, 413-433. [CrossRef]

87. Ferreroc, F.; Perbolib, G.; Rosano, M.; Vesco, A. Car-sharing services: An annotated review. Sustain. Cities Soc. 2018, 37, 501-518. [CrossRef]

88. Jorge, D.; Molnar, G.; Correia, G. Trip pricing of one-way station-based carsharing networks with zone and time of day price variations. Transp. Res. Part B 2015, 81, 461-482. [CrossRef]

89. Perboli, G.; Ferrero, F.; Musso, S.; Vesco, A. Business models and tariff simulation in car-sharing services. Transp. Res. Part A 2017, 115, 32-48. [CrossRef]

90. Illgen, S.; Hoeck, M. Literature review of the vehicle relocation problem in one-way car sharing networks. Transp. Res. Part B 2019, 120, 193-204. [CrossRef]

(C) 2020 by the authors. Licensee MDPI, Basel, Switzerland. This article is an open access article distributed under the terms and conditions of the Creative Commons Attribution (CC BY) license (http://creativecommons.org/licenses/by/4.0/). 